\title{
mTOR Attenuation with Rapamycin Reverses Neurovascular Uncoupling and Memory Deficits in Mice Modeling Alzheimer's Disease
}

\author{
Candice E. Van Skike, ${ }^{1,2}$ Stacy A. Hussong, ${ }^{1,3}$ Stephen F. Hernandez, ${ }^{1,2}$ Andy Q. Banh, ${ }^{1,2}$ Nicholas DeRosa, ${ }^{1,2}$ and \\ Veronica Galvan ${ }^{1,2,3}$ \\ ${ }^{1}$ Barshop Institute for Longevity and Aging Studies, Department of Cellular and Integrative Physiology, University of Texas Health San Antonio, \\ San Antonio, Texas 78229, ${ }^{2}$ The Glenn Biggs Institute for Alzheimer's \& Neurodegenerative Diseases, University of Texas Health San Antonio, San \\ Antonio, Texas 78229, and ${ }^{3}$ Department of Veterans Affairs, South Texas Veterans Health Care System, San Antonio, Texas 78229
}

Vascular dysfunction is a universal feature of aging and decreased cerebral blood flow has been identified as an early event in the pathogenesis of Alzheimer's disease (AD). Cerebrovascular dysfunction in AD includes deficits in neurovascular coupling (NVC), a mechanism that ensures rapid delivery of energy substrates to active neurons through the blood supply. The mechanisms underlying NVC impairment in AD, however, are not well understood. We have previously shown that mechanistic/mammalian target of rapamycin (mTOR) drives cerebrovascular dysfunction in models of AD by reducing the activity of endothelial nitric oxide synthase (eNOS), and that attenuation of mTOR activity with rapamycin is sufficient to restore eNOS-dependent cerebrovascular function. Here we show mTOR drives NVC impairments in an AD model through the inhibition of neuronal NOS (nNOS)- and non-NOS-dependent components of NVC, and that mTOR attenuation with rapamycin is sufficient to restore NVC and even enhance it above WT responses. Restoration of NVC and concomitant reduction of cortical amyloid- $\beta$ levels effectively treated memory deficits in 12-month-old hAPP(J20) mice. These data indicate that mTOR is a critical driver of NVC dysfunction and underlies cognitive impairment in an AD model. Together with our previous findings, the present studies suggest that mTOR promotes cerebrovascular dysfunction in AD, which is associated with early disruption of nNOS activation, through its broad negative impact on nNOS as well as on non-NOS components of NVC. Our studies highlight the potential of mTOR attenuation as an efficacious treatment for AD and potentially other neurologic diseases of aging.

Key words: Alzheimer's disease; cerebral blood flow; cerebrovascular dysfunction; mTOR; neurovascular coupling; nNOS

Significance Statement

Failure of the blood flow response to neuronal activation [neurovascular coupling (NVC)] in a model of AD precedes the onset of AD-like cognitive symptoms and is driven, to a large extent, by mammalian/mechanistic target of rapamycin (mTOR)-dependent inhibition of nitric oxide synthase activity. Our studies show that mTOR also drives AD-like failure of non-nitric oxide (NO)-mediated components of NVC. Thus, mTOR attenuation may serve to treat AD, where we find that neuronal NO synthase is profoundly reduced early in disease progression, and potentially other neurologic diseases of aging with cerebrovascular dysfunction as part of their etiology.

Received Aug. 12, 2020; revised Feb. 19, 2021; accepted Mar. 2, 2021.

Author contributions: C.E.V.S., S.A.H., and V.G. designed research; C.E.V.S., S.A.H., S.F.H., A.Q.B., and N.D. performed research; C.E.V.S., S.A.H., and S.F.H. analyzed data; C.E.V.S., S.A.H., S.F.H., and V.G. wrote the paper.

This research was supported by National Institutes of Health (NIH) | National Institute on Aging (NIA) Grants 1R01-AG-057964-01 and 1R01-AG-068283-01 (to V.G.), U.S. Department of Veterans Affairs Biomedical Laboratory Research and Development Service Merit Review Award 101 BX002211$01 A 2$ (to V.G.), San Antonio Nathan Shock Center of Excellence in the Biology of Aging Grant NIA 2P30-AG-013319-21 (to V.G.), the San Antonio Medical Foundation (to V.G.), and the J.M.R. Barker Foundation (to V.G.). V.G. received support from the Robert L. Bailey and daughter Lisa K. Bailey Alzheimer's Fund in memory of Jo Nell Bailey. In addition, research was supported by Alzheimer's Association Grant AARF-17-504221 (to C.E.V.S.), U.S. Department of Veteran's Affairs Biomedical
Laboratory Research and Development Grant CDA-2 IK2 BX003798-01A1 (to S.A.H.), NIH Kirschstein Predoctoral Individual National Research Service Award 1F31-AG067732-01 (to A.Q.B.), and NIH South Texas Medical Scientist Training Program Grant T32-GM-113896 (to A.Q.B.). These studies used the services of the Healthspan and Functional Assessment Core and the Pathology Core of the San Antonio Nathan Shock Center of Excellence in the Biology of Aging (NIH/NIA Grant 2P30-AG-01331921). Human tissue was obtained from the NIH NeuroBioBank.

The authors declare no competing financial interests.

Correspondence should be addressed to Veronica Galvan at GalvanV@UTHSCSA.edu.

https://doi.org/10.1523/JNEUROSCI.2144-20.2021

Copyright $\odot 2021$ the authors 


\section{Introduction}

Strong evidence indicates that cerebrovascular dysfunction is an early event in the pathogenesis of Alzheimer's disease (AD), preceding memory impairment, brain atrophy, deposition of pathogenic amyloid- $\beta(\mathrm{A} \beta)$ and tau, and clinical diagnosis of $\mathrm{AD}$ (Hays et al., 2016; Iturria-Medina et al., 2016). Normal brain function is dependent on cerebral blood flow (CBF) to deliver a continuous supply of oxygen and glucose, which must be rapidly increased during neuronal activity to meet the energy requirements of active neurons. Regional increases in CBF are linked to neuronal activity through a mechanism known as neurovascular coupling (NVC) or functional hyperemia, mediated by complex signaling events involving neurons, astrocytes, vascular smooth muscle cells, pericytes, and endothelial cells (Attwell et al., 2010; Lecrux and Hamel, 2011; Kisler et al., 2017; Tarantini et al., 2017a). Changes in NVC can significantly impact cognitive function (Iadecola, 2013; Sorond et al., 2013; Tarantini et al., 2015), and NVC deficits in patients with AD (Hock et al., 1997; Rombouts et al., 2000, 2005; Girouard and Iadecola, 2006) are recapitulated in various mouse models of the disease (Shin et al., 2007; Park et al., 2014; Lourenço et al., 2017; Tarantini et al., 2017b).

While astrocyte-derived mediators and other factors contribute to NVC (Attwell et al., 2010; MacVicar and Newman, 2015; Muñoz et al., 2015; Tarantini et al., 2017a), neuronal nitric oxide synthase (nNOS) has a prominent role in the regulation of NVC through the production of NO, released by neurons in an activity-dependent manner (Dirnagl et al., 1993; Cholet et al., 1996; Buerk et al., 2003). In addition, recent studies showed that NO derived from endothelial NOS (eNOS) also contributes to NVC through retrograde propagation of vasodilation (Chen et al., 2014; Toth et al., 2015). The relative contributions of nNOS and eNOS to NVC and how these activities are impacted in AD have yet to be defined.

We previously showed that the mammalian/mechanistic target of rapamycin (mTOR) is a critical mediator of cerebrovascular dysfunction (Van Skike and Galvan, 2018) in models of AD (Lin et al., 2013, 2017; Van Skike et al., 2018), in models of vascular cognitive impairment (Jahrling et al., 2018; Van Skike et al., 2018), and in normative aging (Van Skike et al., 2020). These studies showed that mTOR decreases eNOS activity, and that the restoration of $\mathrm{CBF}$ in $\mathrm{AD}$ model mice by $\mathrm{mTOR}$ attenuation is critically dependent on the restoration of eNOS function (Lin et al., 2013). In the present study, we sought to determine whether mTOR is implicated in NVC deficits in a model of AD [hAPP (J20) mice; Hsia et al., 1999; Mucke et al., 2000; Nicolakakis et al., 2008; Tong et al., 2009; Ongali et al., 2014; Royea et al., 2017] that recapitulates this and other aspects of cerebrovascular dysfunction in $\mathrm{AD}$, and define whether, in addition to eNOS, mTOR may also regulate nNOS function. Our studies show that mTOR potently reduces nNOS activation and activity of nonNOS components of the NVC response to produce NVC deficits in hAPP(J20) mice. Recent studies of the Alzheimer's Disease Neuroimaging Initiative suggest that cerebrovascular deficits arise as the earliest and most profound injury in $\mathrm{AD}$ progression (Iturria-Medina et al., 2016). We found that, similar to human $\mathrm{AD}, \mathrm{NVC}$ deficits precede memory impairment in the hAPP (J20) mouse model. Further, treatment with rapamycin for 2 months, which began 3 months after the onset of AD-like disease, negated established AD-like NVC and cognitive deficits and decreased cortical amyloid levels in hAPP(J20) mice. Together, our data indicate that $\mathrm{mTOR}$ drives early NVC deficits in the hAPP(J20) mouse model of AD through the inhibition of
nNOS and non-NOS components of the response, and that attenuation of $\mathrm{mTOR}$ with rapamycin is sufficient to restore $\mathrm{NVC}$, reduce $\mathrm{A} \beta$, and improve contextual memory in this model of AD.

\section{Materials and Methods \\ Mice}

We performed three independent experiments using separate cohorts of wild-type (WT) littermate mice and heterozygous transgenic mice expressing a human amyloid precursor protein (APP) minigene encoding hAPP695, hAPP751, and hAPP770 carrying the Swedish and Indiana familial $\mathrm{AD}$ mutations driven by the PDGF- $\beta$-chain promoter [hAPP(J20) mice; Hsia et al., 1999; Mucke et al., 2000] generated in our colony, that was originally generated from breeders provided by Lennart Mucke (Gladstone Institute of Neurologic Disease, University of California, San Francisco) and is maintained using transgenic breeders generated in-house or obtained from the JAX colony (The Jackson Laboratory), with the latter introduced every two to three generations. as described previously (Galvan et al., 2006; Banwait et al., 2008; Lin et al., 2013; Pierce et al., 2013; Cremers et al., 2016). Transgenic male hAPP (J20) mice were randomly assigned to receive chow supplemented with either microencapsulated rapamycin $(14 \mathrm{ppm})$ or vehicle-supplemented chow, containing the inactive EUDRAGIT microencapsulation material, prepared and administered as previously described (Harrison et al., 2009; Spilman et al., 2010; Halloran et al., 2012; Pierce et al., 2013; Jahrling et al., 2018; Van Skike et al., 2018). This diet formulation provided the animals with an estimated $1.65 \mathrm{mg} / \mathrm{kg} / \mathrm{d}$ rapamycin, which was calculated using the average amount of food consumed per mouse within a group-housed cage ( $\leq 5$ animals/cage) during these studies. Nontransgenic male littermates were used as WT controls and were maintained on EUDRAGIT-supplemented chow. Mice were treated with experimental diets for 8 months starting at 4 months of age (and tested at 12 months of age; cohort 1 ) or for 2 months starting at 4 months of age (cohort 2) or 10 months of age (cohort 3), and tested at 6 or 12 months of age, respectively. Figure $1 A$ details the experimental timeline for treatment and testing of separate cohorts. Animals had continuous access to diets and water. All studies were approved by the University of Texas Health San Antonio Institutional Animal Care and Use Committee and complied with ARRIVE (Animal Research: Reporting of In Vivo Experiments) guidelines.

\section{Neurovascular coupling}

NVC was measured using laser Doppler flowmetry, based on previously reported methods (Royea et al., 2017), by an experimenter blinded to genotype and treatment condition. Animals were anesthetized with a combination of urethane and $\alpha$-chloralose (750 and $50 \mathrm{mg} / \mathrm{kg}$, respectively) and placed in a stereotaxic frame on a heating pad to maintain body temperature at $37^{\circ} \mathrm{C}$. Blood oxygen saturation, heart rate, respiration rate, and blood pressure were continuously monitored using PhysioSuite (Kent Scientific). Measurements of baseline NVC and NVC with nNOS inhibited were performed in $<20 \mathrm{~min}$, a time during which mouse physiological parameters, including blood gas levels, are stable (Tong et al., 2012; Ongali et al., 2014). The bone over the left somatosensory barrel cortex (0.5-1.5 $\mathrm{mm}$ posterior and 3-4.5 $\mathrm{mm}$ lateral from bregma) was removed, a silicone elastomer barrier (World Precision Instruments) was made around the craniotomy, artificial CSF (aCSF) was applied, and a laser Doppler probe (Transonic) was positioned over the barrel cortex. NVC was measured as increased CBF relative to baseline in response to contralateral electrical whisker stimulation $(30 \mathrm{~s}$ at $5 \mathrm{~Hz}$ and $1 \mathrm{~mA}$, with $90 \mathrm{~s}$ intervals). Changes in CBF were expressed as the fold increase relative to average baseline $\mathrm{CBF}$ collected during the $30 \mathrm{~s}$ prestimulus and poststimulus. A schematic diagram of the NVC procedure can be found in Figure $1 B$.

Selectivity of small-molecule enzyme inhibitors depends strongly on their concentration (Ayajiki et al., 2001). Prior studies have shown that $N$ - $\omega$-propyl-L-arginine (L-NPA) has 150-fold selectivity for the inhibition of the nNOS isoform (NOS1) versus the eNOS isoform (NOS3) and 3158 -fold selectivity for nNOS versus the inducible NOS (iNOS) isoform 
A

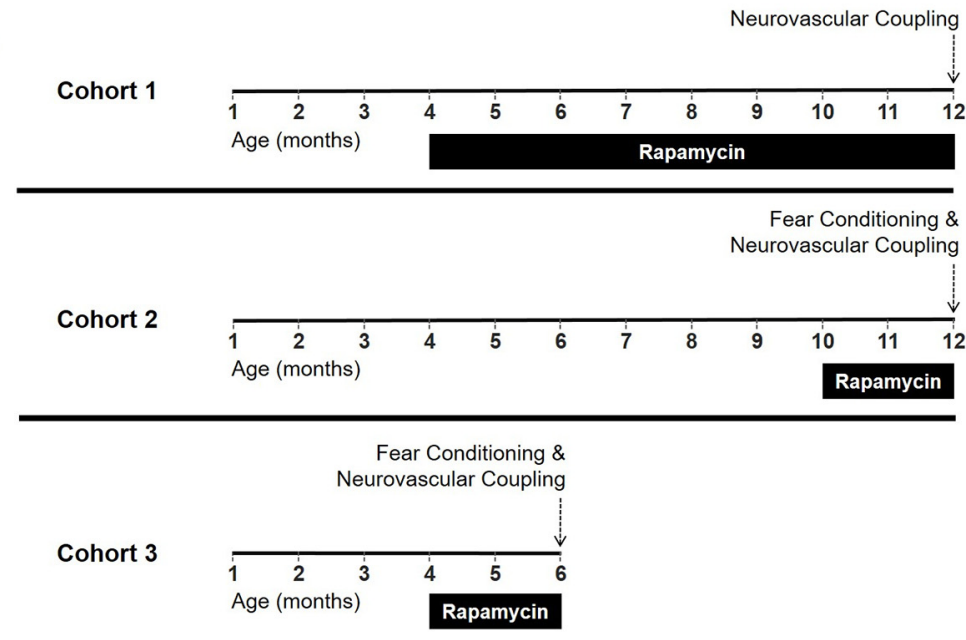

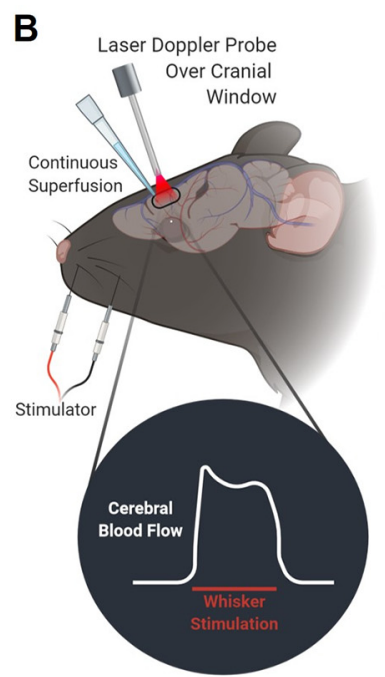

Figure 1. Diagram of experimental design and schematic diagram of laser Doppler flowmetry to measure neurovascular coupling. $\boldsymbol{A}$, Timeline showing the age at which rapamycin- or vehicle-containing diets were administered and outcome measures were assessed for the three experimental cohorts. $\boldsymbol{B}, \mathrm{A}$ laser Doppler probe is positioned over the barrel cortex using an open cranial window preparation. A silicone elastomer barrier encircles the window to allow continuous superfusion of aCSF or aCSF containing nitric oxide synthase inhibitors. Neurovascular coupling is measured as the change in cerebral blood flow relative to baseline during whisker stimulation evoked by pulses of electrical current delivered to the whisker pad. $\boldsymbol{B}$ was created with BioRender.

(NOS2; Zhang et al., 1997) when used at concentrations close to its $\mathrm{K}_{\mathrm{i}}$ (inhibition constant) for nNOS (57 nM; Zhang et al., 1997), and is selective for nNOS over other NOS isoforms in vivo (Yang et al., 1999; Bonvento et al., 2000; Burke and Bührle, 2006; Stefanovic et al., 2007; Kato et al., 2009; Beamer et al., 2012; Sousa et al., 2015; Lubomirov et al., 2017; Almeida et al., 2019). This is in contrast to reports by Overend and Martin (2007) and Pigott et al. (2013) that used L-NPA at concentrations up to $1000 \times$ higher than the $\mathrm{K}_{\mathrm{i}}$ for nNOS in ex vivo models, where they found, not surprisingly, nonspecific inhibition of eNOS. Thus, we used L-NPA in vivo at $200 \mathrm{nM}, 3.5 \times$ higher than the $\mathrm{K}_{\mathrm{i}}$ of $\mathrm{L}-\mathrm{NPA}$ for $\mathrm{nNOS}$, where no significant inhibition of eNOS or iNOS is expected. Validating this assumption, and in contrast with the impact of general NOS inhibition with $10 \mu \mathrm{M} \mathrm{N}$ - $\omega$-nitro-L-arginine methyl ester (L-NAME; Fig. 2A; Iadecola et al., 1993; Dirnagl et al., 1994; Leithner et al., $2010)$, superfusion with $200 \mathrm{~nm} \mathrm{~L}-\mathrm{NPA}\left(3.5 \times\right.$ its $\left.\mathrm{K}_{\mathrm{i}}\right)$ did not have any impact on endothelium-dependent, acetylcholine (ACh)induced vasodilation, which is eNOS-mediated, in WT mice (Fig. $2 A$ ). These data rule out nonspecific actions of $200 \mathrm{~nm} \mathrm{~L}-\mathrm{NPA}$ on eNOS. The concentration of L-NPA (200 nM) that selectively inhibits nNOS in vivo (Fig. $2 A$ ) is 900 -fold lower than the $\mathrm{K}_{\mathrm{i}}$ of $\mathrm{L}$-NPA for iNOS $\left(K_{\mathrm{i}}=180 \mu \mathrm{M}\right.$; Zhang et al., 1997); thus nonspecific inhibition of iNOS by $200 \mathrm{nM} \mathrm{L-NPA}$ in vivo is unlikely.

After measuring baseline NVC in the presence of aCSF, to effectively and specifically inhibit nNOS we superfused $200 \mathrm{nM} \mathrm{L-NPA}$ continuously for 10 min before additional NVC measurements (Zhang et al., 1997). To define the contribution of eNOS to NVC, after superfusion with 200 nM L-NPA, we superfused a combination of $200 \mathrm{nM} \mathrm{L}-\mathrm{NPA}$ and $10 \mu \mathrm{M} \mathrm{L}-$ NAME, a nonselective NOS inhibitor, for $10 \mathrm{~min}$ before NVC measurements. Since nNOS activity had been previously blocked with L-NPA, additional decreases in NVC observed after the addition of L-NPA ${ }_{\mathrm{L}-}$ NAME defined the specific contribution of eNOS to NVC. Potential contributions of iNOS to NVC are unlikely since iNOS is continuously active when induced (Stuehr, 1999).

By using a specific nNOS inhibitor (L-NPA) at concentrations close to its $\mathrm{K}_{\mathrm{i}}$ for the enzyme, we were able to isolate the nNOS contribution to NVC from that of eNOS, which was revealed as the residual, L-NAME-sensitive activity during NVC while in the presence of L-NPA. We did not use L-NAME alone in our NVC studies only because L-NAME potently inhibits all NOS isoforms (including nNOS and eNOS); thus, the application of L-NAME alone would have informed the role of NOS in general during NVC but not advance our goal of discerning the changes in the individual contribution of nNOS and eNOS to
NVC during AD-like progression in model mice, and the impact of mTOR attenuation with rapamycin on the individual NOS isoforms.

The average of three stimulations for each of the three conditions examined [baseline (aCSF vehicle), L-NPA, and L-NPA + L-NAME] were plotted for each animal and the area under the curve during stimulation, with baseline normalized to 1 , was calculated. The nNOS-dependent, the non-nNOS, L-NAME-sensitive (eNOS)-dependent, and the non-NOSdependent contributions to NVC were calculated as (1) the percentage reduction in NVC by L-NPA compared with baseline vehicle stimulation; (2) the percentage reduction in NVC by subsequent $\mathrm{L}-\mathrm{NPA}+\mathrm{L}-\mathrm{NAME}$ application relative to vehicle stimulation, subtracting the percentage reduction by L-NPA alone to isolate the unique contribution of eNOS; and (3) the remaining magnitude of the non-NOS-mediated NVC response after subtraction of the percentage reduction by L-NPA alone and by LNPA+ L-NAME, respectively. Data were analyzed with a two-way ANOVA (Group $\times$ NOS condition) followed by Tukey's post hoc test.

\section{Contextual fear conditioning}

To measure hippocampal-dependent contextual memory, animals underwent contextual fear conditioning before NVC assessment. Mice were acclimated to the testing environment for $4 \mathrm{~h}$ before being placed into test cages within isolation chambers (Coulbourn Instruments) and exposed to two pairings of a $30 \mathrm{~s}$ auditory stimulus (white noise), which coterminated with a $2 \mathrm{~s}$ footshock ( $1 \mathrm{~mA})$. Twentyfour hour recall of hippocampal-dependent contextual memory was assessed during a 5 min exposure to the context itself, conducted in the absence of any tone or shock. FreezeFrame software (Coulbourn Instruments) was used to record, monitor, and quantify freezing behavior. The percentage of time spent freezing was calculated for each mouse, and mice were excluded if $<15 \%$ freezing, indicative of hyperactivity, was detected. This resulted in the exclusion of four animals from the behavioral studies performed with 6month-old animals (one animal each from the WT and hAPP+ rapamycin groups, and two from the hAPP+vehicle group; cohort 3). No animals were excluded from the studies conducted on 12-month-old mice (cohort 2). Data were analyzed using a one-way ANOVA followed by Tukey's multiple-comparison test among all means.

\section{Isolation of mouse brain microvasculature}

These methods are based on those previously described (Wu et al., 2003) and used (Van Skike et al., 2018). Subsequent to NVC, the brain was extracted, and large pial vessels were removed. One hemibrain was minced into small pieces and gently homogenized in MCDB131 medium (Thermo 

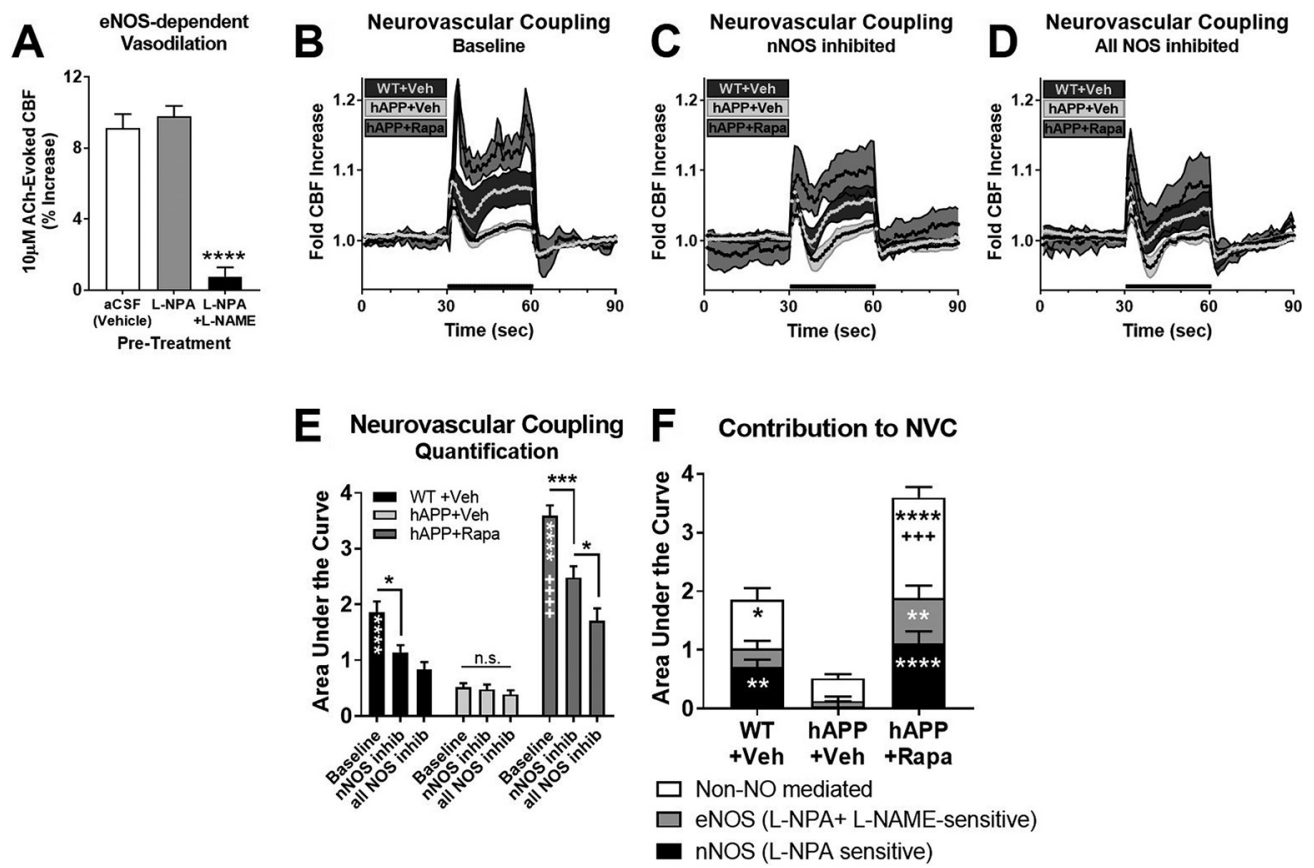

Figure 2. Attenuation of mTOR prevents neurovascular uncoupling in 12-month-old hAPP(J20) mice. A, L-NPA at 200 nm has no impact on endothelium-dependent, eNOS-mediated, AChinduced vasoreactivity. Pretreatment with L-NPA, a selective nNOS inhibitor, at $200 \mathrm{~nm}$ (close to its $\mathrm{K}_{\mathrm{i}}$ for nNOS) has no impact on endothelium-dependent, eNOS-mediated vasoreactivity induced by superfusion of $10 \mu \mathrm{m}$ ACh (Tukey's test, $q_{(8)}=0.94, p=0.79$ vs aCSF vehicle). In contrast, superfusion with $200 \mathrm{~nm}$ L-NPA together with $10 \mu \mathrm{M} \mathrm{L-NAME}$, a general NOS inhibitor, profoundly inhibited ACh-induced CBF increases $\left(91.7 \%\right.$ inhibition, $q_{(8)}=13.64$, ****p $\left.<0.0001\right) . \boldsymbol{B}-\boldsymbol{D}$, NVC responses in hAPP mice; the fold change in CBF during whisker pad stimulation ( $30 \mathrm{~s}$; bold black line) was measured sequentially in the presence of aCSF (vehicle; $\boldsymbol{B}$ ), $200 \mathrm{~nm} \mathrm{L-NPA}$ to inhibit nNOS (Fig. 2A; $\boldsymbol{C}$ ), and $200 \mathrm{~nm}$ L-NPA plus $10 \mu \mathrm{m} \mathrm{L-NAME}$ (D) to inhibit all remaining NOS activity (i.e., eNOS). $E$, NVC responses during $30 s$ whisker stimulations. Area under the curve was calculated as an increase relative to baseline (i.e., only upward peaks). Baseline NVC is impaired in hAPP(J20) mice compared with WT littermates $\left(q_{(27)}=10.41\right.$, $\left.* * * * p<0.0001\right)$. These deficits were negated by 8 months of rapamycin (Rapa; $q_{(27)}=22.02$, $* * * * p<0.0001)$ and enhanced compared with WT $\left(q_{(27)}=11.91,{ }^{++++} p<0.0001\right)$. Inhibition of nNOS with $200 \mathrm{nM} \mathrm{L-NPA} \mathrm{significantly} \mathrm{reduced} \mathrm{NVC} \mathrm{in} \mathrm{WT}\left(q_{(27)}=5.24\right.$ vs baseline, $* p=0.02)$, but not in hAPP(J20) mice $\left(q_{(27)}=0.38, p=0.99\right.$ vs baseline), suggesting a preexisting nNOS deficit in hAPP(J20) animals that was negated by rapamycin treatment $\left(q_{(27)}=7.14\right.$ vs baseline, $* * * p=0.0008$ ). The remaining NVC response in the presence of L-NPA plus L-NAME (inhibiting all remaining NOS activity; i.e., eNOS) was not significantly decreased with respect to L-NPA treatment in WT mice $\left(q_{(27)}=2.31, p=0.78\right)$ or in $\mathrm{hAPP}(J 20)$ mice $\left(q_{(27)}=0.76, p=0.99\right)$ but was enhanced in rapamycin-treated hAPP(J20) mice (L-NPA+L-NAME vs L-NPA, $\left.q_{(27)}=4.92, * p=0.039\right)$. $\boldsymbol{F}$, Relative contributions of nNOS, eNOS, and non-NO components to total NVC. Profound deficits in nNOS-dependent NVC in hAPP(J20) mice (compared with WT; $\left.q_{(27)}=5.21, * * p=0.003\right)$ are negated by rapamycin treatment $\left[q_{(27)}=7.70, * * * * p<0.0001\right.$, vs hAPP(J20)]. Attenuation of mTOR by rapamycin enhanced non-nNOS-mediated, L-NAME-sensitive (eNOS) contributions to NVC in rapamycin-treated hAPP(J20) mice $\left[q_{(27)}=4.85, * * p=0.005\right.$ vs hAPP(J20); $\left.q_{(27)}=3.13\right]$. Deficits in the remaining non-N0-mediated NVC response in hAPP(J20) mice $\left(q_{(27)}=3.50, * p=0.049\right.$ vs WT) are negated $\left(q_{(27)}=9.48, * * * * p<0.0001\right.$ vs vehicle-treated hAPP) and enhanced $\left(q_{(27)}=6.01,+++p=0.0006\right.$ vs WT) in rapamycin-treated hAPP(J20) mice. For all panels, data are the mean \pm SEM of $n=3-5 /$ group; post hoc tests are Tukey's multiple-comparisons tests. Unless otherwise indicated, asterisks (*) in the figure represent a significant difference relative to hAPP + vehicle (Veh) and pluses $(+)$ represent a significant difference relative to WT+Veh.

Fisher Scientific) with $2 \%$ cosmic calf serum (CCS; HyClone) using a dounce tissue grinder with a large clearance pestle. The homogenate was mixed with a final volume of $17 \%$ dextran $(\sim 70,000$ molecular weight; Sigma-Aldrich) in MCDB131 medium with 2\% CCS and centrifuged at $10,000 \mathrm{rpm}$ for $15 \mathrm{~min}$ at $4^{\circ} \mathrm{C}$ in a swing bucket rotor (Beckman SW $40 \mathrm{Ti}$, Beckman Coulter). The pellet containing the brain microvessels was resuspended in $1 \times$ lysis buffer [Cell Signaling Technology (CST)] with protease inhibitors (cOmplete, Mini, Roche Diagnostics). The lysate was sonicated briefly and centrifuged at $12,000 \times \mathrm{g}$ for $15 \mathrm{~min}$ at $4^{\circ} \mathrm{C}$ to remove cellular debris.

\section{Cell culture and treatment}

Mouse neuroblastoma N2a cells were cultured using Eagle's Minimum Essential Medium (catalog \#30-2003, ATCC) containing 10\% CCS and 1\% penicillin/streptomycin (Sigma-Aldrich). Cells were grown to $\sim 75 \%$ confluency in a $37^{\circ} \mathrm{C}$ incubator with $5 \% \mathrm{CO}_{2}$ and then treated with 5.5 nм rapamycin for $24 \mathrm{~h}$ to inhibit mTORC1 activity. Cells were washed with PBS and harvested with $1 \times$ cell lysis buffer (CST) with protease inhibitors (cOmplete, Mini, Roche Diagnostics). Cell lysates were sonicated briefly and then centrifuged at $12,000 \times \mathrm{g}$ for $15 \mathrm{~min}$ at $4^{\circ} \mathrm{C}$ to remove cellular debris.

Human brain tissue

Frozen human brain tissue was obtained through the NIH NeuroBioBank. Brain tissue lysates were prepared from the hippocampal formation of $\mathrm{AD}$ patients with Braak stage III (mean age, 85.6 years; $n=3$ ), Braak stage IV (mean age, 84 years; $n=3$ ), Braak stage V (mean age, 91.3 years; $n=3$ ), and Braak stage VI (mean age, 68.7 years; $n=3$ ) pathology as determined on autopsy, and from non-AD control subjects in whom Parkinson's disease was diagnosed (mean age, 81 years; $n=3$ ). The frozen tissue block from the hippocampal formation was powdered in liquid nitrogen using a mortar and pestle. Samples were solubilized and briefly sonicated in lysis buffer containing $50 \mathrm{~mm}$ Tris, $\mathrm{pH}$ 7.5, 150 $\mathrm{mm} \mathrm{NaCl}, 10$ mм EDTA, $1 \%$ Triton X-100 with complete mini protease inhibitor (Roche), and HALT phosphatase inhibitor (Thermo Fisher Scientific). Samples were centrifuged for $15 \mathrm{~min}$ at $12,000 \times \mathrm{g}$ at $4^{\circ} \mathrm{C}$, and the supernatant was used for relative quantification of total nNOS expression normalized to vinculin with automated Western blotting (described below).

\section{Protein quantification}

Protein concentrations were determined using a colorimetric protein assay based on the Bradford method (BIO-RAD). Automated Western blots were performed using the Wes capillary electrophoresis system (ProteinSimple). Primary antibodies for ribosomal protein S6 (rpS6; catalog \#2217, CST), phospho-rpS6 (S240/S244; catalog \#2215, CST), nNOS (catalog \#sc-5302, Santa Cruz Biotechnology), phospho-nNOS (S1412; catalog \#NBP1-97488, Novus Biologicals), eNOS (catalog \#AF950, R\&D Systems), Hsp90 (catalog \#4877, CST), vinculin (catalog \#MCA465GA, BIO-RAD), and $\beta$-actin (catalog \#4970, CST) were used 

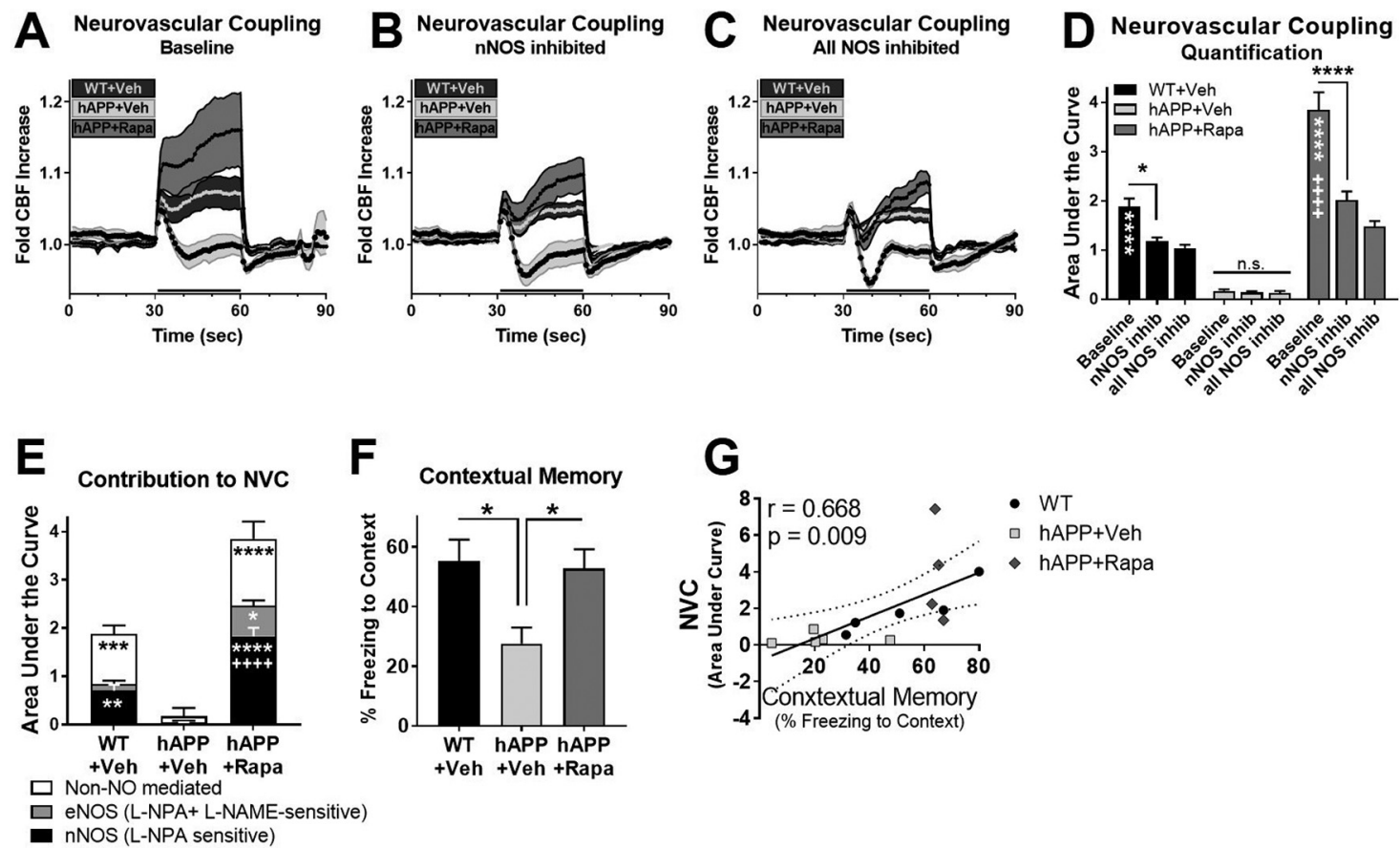

Figure 3. Short-term mTOR attenuation reverses NVC impairments in 12-month-old hAPP(J20) mice. $A-C$, Fold change in cerebral blood flow are the mean \pm SEM of $n=4-5 /$ group during whisker pad stimulation ( $30 \mathrm{~s}$, bold black line), stimulations conducted sequentially in the presence of aCSF [vehicle (Veh); $\boldsymbol{A}$ ], $200 \mathrm{~nm}$ L-NPA to inhibit nNOS specifically (Fig. 2A; $\boldsymbol{B}$ ), and 200 nм L-NPA $+10 \mu$ m L-NAME $(C)$ to inhibit all NOS, thus defining the contribution of the non-nNOS-dependent, L-NAME-sensitive eNOS. D, NVC responses during $30 \mathrm{~s}$ whisker stimulations. Area under the curve was calculated as an increase relative to baseline (i.e., only upward peaks). Baseline NVC impairments in hAPP(J20) mice relative to WT $\left(q_{(33)}=12.81, * * * * p<0.0001\right)$ are reversed by 2 months of rapamycin (Rapa; $\left.q_{(33)}=26.01, * * * * p<0.0001\right)$, with enhancement of NVC in rapamycin-treated hAPP(J20) mice compared with WT $\left(q_{(33)}=13.93\right.$, $* * * * p<0.0001)$. L-NPA superfusion significantly reduces NVC in WT mice $\left(q_{(33)}=5.25, * p=0.02\right)$, but not in hAPP(J20) mice $\left(q_{(33)}=0.22, p>0.99\right)$, suggesting a preexisting nNOS deficit in this group that is restored by rapamycin treatment in the hAPP(J20) + rapamycin group, indicated by a significant inhibition of NVC in the presence of $200 \mathrm{~nm} \mathrm{L-NPA}\left(q_{(33)}=12.28\right.$ vs baseline, $* * * * p<0.0001$ ). The remaining NVC response in the presence of L-NPA+ L-NAME (inhibiting all remaining NOS activity; i.e., eNOS) was not significantly different versus L-NPA alone in WT $\left(q_{(33)}=1.05, p=0.99\right), \operatorname{hAPP}(J 20)\left(q_{(33)}=0.09, p>0.99\right)$, or in hAPP(J20) + rapamycin $\left(q_{(33)}=3.60, p=0.24\right)$. $\boldsymbol{E}$, Contributions of nNOS, eNOS, and non-NOS components to total NVC. Deficits in nNOS-dependent NVC in hAPP(J20) mice $\left(q_{(33)}=4.47, * * p=0.009\right.$ vs WT) are negated by mTOR inhibition in rapamycin-treated hAPP(J20) mice $\left(q_{(33)}=11.31, * * * * p<0.0001\right.$ vs hAPP) and nNOS-dependent NVC is enhanced over WT $\left(q_{(33)}=7.10,{ }^{++++} p<0.0001\right)$. Additionally, rapamycin enhances L-NAME-sensitive activities (eNOS) in hAPP(J20) mice relative to vehicle-treated hAPP(J20) mice $\left(q_{(33)}=3.93, * p=0.02\right)$. Deficits in the remaining non-N0-mediated NVC response in hAPP $(J 20)$ mice $\left(q_{(33)}=6.06, * * * p=0.0004\right.$ vs WT) are negated in rapamycin-treated hAPP(J20) mice $\left[q_{(33)}=7.87, * * * * p<0.0001\right.$ vs vehicle-treated hAPP(J20) mice]. $\boldsymbol{F}$, Hippocampal-dependent contextual memory impairment in 12-month-old hAPP(J20) mice [hAPP(J20) vs WT, $\left.q_{(16)}=4.19, * p=0.024\right]$ is negated by 2 months of rapamycin treatment $\left[q_{(16)}=3.93, * p=0.034\right.$, hAPP(J20) vs hAPP(J20) + rapamycin]. G, Baseline NVC response is correlated with contextual memory performance $(r=0.668, p=0.009)$. Behavioral studies used $n=6-7$ mice/group. All post hoc analyses are Tukey's multiple-comparisons tests. Unless otherwise indicated, asterisks $(*)$ in the figure represent a significant difference relative to hAPP + Veh and pluses $(+)$ represent a significant difference relative to WT+Veh.

with the appropriate anti-mouse, anti-rabbit, or anti-goat secondary antibodies (ProteinSimple). Data were analyzed as the area under the curve of the electropherogram and were normalized to control. Unpaired $t$ tests were used to identify differences between group means. A nonparametric Spearman's correlation coefficient was used to calculate the correlation between nNOS abundance and Braak stage.

\section{$A \beta 40$ and $A \beta 42$ quantification}

A fragment of the left frontal cortex obtained from frozen brain was solubilized in $5 \mathrm{M}$ guanidine overnight with orbital rotation at $4^{\circ} \mathrm{C}$ as per the manufacturer instructions (Thermo Fisher Scientific). Guanidine lysates were diluted and used in the ELISAs to quantitate human $\mathrm{A} \beta_{40}$ (catalog \#KHB3481, Thermo Fisher Scientific) and $\mathrm{A} \beta_{42}$ (catalog \#KHB3441, Thermo Fisher Scientific). Data were analyzed using a twoway ANOVA (age $\times$ treatment) followed by Tukey's multiple-comparison test.

\section{Immunofluorescence}

Ten micrometer cortical cryosections from left hemibrain were postfixed in $4 \%$ PFA for $30 \mathrm{~min}$ and washed in TBS. Sections were blocked using $5 \%$ BSA plus $5 \%$ goat serum in TBS for $1 \mathrm{~h}$ at room temperature and a primary antibody against amyloid- $\beta$ (4G8; catalog \#800701, BioLegend) was incubated overnight at $4^{\circ} \mathrm{C}$. The tissue sections were washed and incubated with Alexa Fluor 594 conjugated goat anti-mouse secondary antibody (catalog \#A11032, Thermo Fisher Scientific) at room temperature for $1 \mathrm{~h}$, stained with DAPI (catalog \#D1306, Thermo Fisher Scientific), and mounted on coverslips with ProLong Gold Antifade Mountant (Thermo Fisher Scientific). Images were acquired using a Zeiss LSM 780 NLO confocal microscope with a $40 \times$ water-immersion objective and numerical aperture of 1.1, and positive fluorescent immunoreactivity was quantified by a researcher blinded to treatment condition as mean fluorescence intensity using ImageJ Fiji (Schindelin et al., 2012). Tissue from WT controls was included in all experiments to assess the specificity of immunoreactivity. Because a minimal amount of lipofuscin autofluorescence was detected in brains of 12-month-old WT mice [nontransgenic hAPP(J20) littermates], $\mathrm{A} \beta$ immunoreactivity detected as fluorescent signals in hAPP(J20) transgenic groups was normalized to WT controls. Data were analyzed with a two-way ANOVA, followed by Tukey's post hoc tests.

\section{Experimental design and statistical analysis}

Cohort 1. Cohort 1 consisted of NVC in 12-month-old hAPP(J20) mice with three experimental groups, WT+vehicle $(n=4)$, hAPP + vehicle $(n=5)$, and hAPP + rapamycin $(n=4)$, starting treatment at 4 months of age and undergoing testing at 12 months of age (Fig. 2). Group size calculations (G*Power) determined with $n=4$ for NVC, using effect sizes generated from preliminary NVC data, resulted in $90 \%$ power to detect differences of $30 \%$ between experimental group means 
at $\alpha=0.05$ using ANOVA and Tukey's post hoc tests. Although one animal in the hAPP+ rapamycin group died because of anesthetic complications prior to surgical procedures ( $n=3$ for hAPP + rapamycin group), the post hoc power calculations revealed that the actual power achieved in all three experiments performed was $>0.95$.

Analyses of NVC data were performed in GraphPad Prism version 7.03. Area under the curve during stimulation (increase from baseline and only upward peaks) for each animal was calculated for baseline, during L-NPA superfusion, and during L-NPA + L-NAME superfusion) and used in a two-way ANOVA (group $\times$ NOS condition) followed by Tukey's post hoc test among all group means. The percentage contribution to NVC was calculated as described above and data were analyzed with a two-way ANOVA (group $\times$ NOS), followed by Tukey's test for simple effects within the different inhibitor treatments (to determine group differences within the different NOS conditions).

Cohorts 2 and 3. Cohorts 2 and 3 consisted of cognitive testing and NVC in 12-month-old (cohort 2, Fig. 3) and 6-month-old (cohort 3, Fig. 4) groups after 2 months of treatment. For both groups, we calculated group sizes using variances previously measured for the most variable outcome, contextual memory in 12-month-old animals. Six animals per group provided $90 \%$ power to detect a $20 \%$ difference in measures of contextual memory at $\alpha=0.05$ using ANOVA and Tukey's test. NVC studies were conducted, and data were analyzed as described for cohort 1. Fear-conditioning data were analyzed with a one-way ANOVA, followed by Tukey's post hoc tests.

Statistical design for cell culture studies and for quantification of amyloid- $\beta$ levels in brain tissue are described in detail in the sections above. Detailed descriptions of statistical analyses of data generated are provided in the relevant figure legends.

\section{Ethics statement}

The authors acknowledge that they have read and that the research was conducted in accordance with the Guidelines for Responsible Conduct Regarding Scientific Communication and the Policies on the Use of Animals in Research of the American Psychological Association.

\section{Results}

Long-term mTOR attenuation started early in AD-like progression negates NVC deficits in the hAPP $(J 20)$ mouse model

In agreement with previous studies (Nicolakakis et al., 2008; Tong et al., 2009; Ongali et al., 2014; Royea et al., 2017, 2020), $\mathrm{CBF}$ increases in the barrel cortex in response to whisker pad stimulation were profoundly reduced in 12-month-old transgenic hAPP(J20) mice (Fig. 2B,E,F). Impaired NVC, however, was negated and the NVC response was enhanced in hAPP(J20) mice with respect to WT mice by 8 months of mTOR attenuation via microencapsulated rapamycin treatment started early in $\mathrm{AD}$ like progression at 4 months of age (Fig. $2 B, E, F$ ).

Neuronal NOS-derived NO contributes significantly to NVC responses (Dirnagl et al., 1993; Cholet et al., 1996). To define a potential role of reduced nNOS activity in NVC deficits of hAPP (J20) mice, in preparative experiments we identified concentrations of L-NPA (a nNOS inhibitor with 150-fold selectivity for nNOS vs eNOS and 3158 -fold selectivity for nNOS vs iNOS when used at concentrations close to its $\mathrm{K}_{\mathrm{i}}, 57 \mathrm{~nm}$; Zhang et al., 1997) that effectively inhibit nNOS but do not impact eNOS-dependent responses in vivo (Fig. $2 A$ ). Consistent with the previously reported magnitude of nNOS contribution to NVC (Lindauer et al., 1999; Bonvento et al., 2000; Kitaura et al., 2007), we found that superfusion of pial vasculature with $200 \mathrm{nM} \mathrm{L-}$ NPA, which blunted CBF increases from somatosensory stimulation in WT mice by $38 \%$ (Fig. 2C,E,F), had no impact on AChinduced, endothelium-dependent, eNOS-mediated vasodilation (Fig. 2A; Furchgott and Zawadzki, 1980; Rosenblum, 1986).
Combined treatment with $200 \mathrm{~nm}$ L-NPA plus $10 \mu \mathrm{m}$ of the nonselective NOS inhibitor L-NAME, on the other hand, completely abolished $\mathrm{CBF}$ responses to ACh (Fig. 2A). Together, these data indicate that $\mathrm{ACh}$-dependent vasoreactivity is mediated by a non-L-NPA-inhibitable, L-NAME-sensitive activity, namely eNOS. A vast majority of small-molecule enzyme inhibitors will show nonspecific activities if used at concentrations that are significantly higher than the $\mathrm{K}_{\mathrm{i}}$ for their target. Prior studies using ex vivo models (organotypic brain slice or aortic ring preparations) claimed that LNPA is nonselective for nNOS inhibition (Pigott et al., 2013); however, these studies used L-NPA at concentrations $\sim 377 \times$ higher than the $\mathrm{K}_{\mathrm{i}}$ for $\mathrm{nNOS}$, thus completely outside of the concentration range to provide selective inhibition of this NOS isoform. Indeed, Pigott et al. (2013) reported that the $\mathrm{IC}_{50}$ for eNOS in an ex vivo model is $21.5 \mu \mathrm{M} \mathrm{L}-\mathrm{NPA}$. Together, our data indicate that L-NPA at concentrations that are $\sim 3 \times$ the $K_{\mathrm{i}}$ of L-NPA for $\mathrm{nNOS}(200 \mathrm{nM} \mathrm{L}$ NPA) can effectively inhibit nNOS without a discernible impact on eNOS-dependent responses in vivo.

To define the potential role of damage to specific NVC mediators in $\mathrm{AD}$-like NVC impairment and to determine the impact of mTOR attenuation on NO-dependent and non-NO-dependent contributions to NVC and how each may drive NVC in hAPP(J20) mice, we measured CBF changes in the exposed barrel cortex after continuous superfusion (Dirnagl et al., 1994; Zhang et al., 1995; Leithner et al., 2010; Toth et al., 2015; Mishra et al., 2016) of topical aCSF, first, to measure baseline (maximal) NVC responses, then, after continuous superfusion of NOS inhibitors with different isoform specificity (i.e., nNOS; Yang et al., 1999; Bonvento et al., 2000; Burke and Bührle, 2006; Stefanovic et al., 2007; Beamer et al., 2012; Sousa et al., 2015) versus all NOS (Iadecola et al., 1993; Dirnagl et al., 1994; Leithner et al., 2010), to define specific contributions of constitutive NOS to NVC. The contribution of NOS activity to NVC responses was measured as the magnitude of the decrement in evoked CBF observed in the presence of each inhibitor (i.e., the magnitude of the L-NPA-sensitive response provided a measure of the contribution of nNOS; the magnitude of $\mathrm{L}-\mathrm{NPA}+\mathrm{L}-\mathrm{NAME}$-sensitive response, measured subsequently, provided a measure of the remaining, non-nNOS NOS contribution). A contribution of $\mathrm{L}^{-}$ NAME-sensitive iNOS activity to NVC is unlikely because (1) iNOS activity is associated with oxidative stress, which inhibits NVC; and (2) no role for iNOS in NVC or mechanisms of regulation for this NOS isoform that are responsive to changes in neuronal activity has been documented. Thus, the magnitude of the non-nNOS, L-NAME-sensitive NVC response in our studies provided a measure of eNOS activity. The magnitude of the remaining NVC response after the inhibition of all NOS provided a measure of non-NO-mediated contributions to NVC.

As mentioned above, and in agreement with prior studies (Lindauer et al., 1999; Bonvento et al., 2000; Kitaura et al., 2007), $200 \mathrm{nM} \mathrm{L}-\mathrm{NPA}$ reduced evoked CBF responses in WT mice by $38 \%$ (Fig. 2C,E,F), indicating that $38 \%$ of the observed NVC response in WT mice was mediated by nNOS. While we cannot confirm complete inhibition of nNOS by $200 \mathrm{nM} \mathrm{L-NPA}$ in our studies, the magnitude of nNOS inhibition that we measured is in agreement with prior measures of the nNOS contribution to NVC using both genetic and pharmacological approaches (Lindauer et al., 1999; Bonvento et al., 2000; Kitaura et al., 2007).

Subsequent superfusion of L-NPA together with a general inhibitor of NOS (L-NAME; Fig. 2D-F) further reduced evoked $\mathrm{CBF}$ responses by $17 \%$ in WT mice, consistent with prior reports of eNOS involvement in NVC (Bell and Zlokovic, 2009; Toth et al., 2015), although this difference did not reach statistical 
significance. Overall, the combined treatment with L-NPA $+_{\mathrm{L}-}$ NAME reduced CBF responses in WT mice by 55\%; the nonNOS-mediated component of NVC (driven by other mechanisms derived from the neurovascular unit including neurons, astrocytes, pericytes, vascular smooth muscle cells, and vascular endothelium; Kisler et al., 2017) thus represented $45 \%$ of the overall response. These data indicate that nNOS and non-NOSdependent mediators combined contribute the largest proportion $(83 \%)$ of the NVC response in WT C57BL/6J mice, and that eNOS mediates a non-nNOS, L-NAME-sensitive component of NVC that is smaller in magnitude.

In contrast to responses in WT mice, pretreatment with $200 \mathrm{~nm}$ L-NPA reduced NVC responses in vehicle-treated hAPP (J20) mice by $7 \%$, and this reduction did not differ significantly from baseline NVC levels in this group (Fig. 2C,E,F), indicating that the nNOS-dependent contribution to NVC is substantially reduced (from $38 \%$ to $7 \%$ ) relative to WT mice or absent (not different from baseline) in hAPP(J20) mice at 12 months of age (Fig. 2E,F). Attenuation of mTOR, however, significantly increased the contribution of $\mathrm{nNOS}$ to NVC in rapamycintreated hAPP $(J 20)$ mice compared with vehicle-treated hAPP (J20) animals (Fig. 2C,E,F), restoring the nNOS-dependent NVC response $(31 \%)$ to levels not significantly different from those of WT mice (Fig. 2F). These data indicate that mTOR activity is required for the loss of nNOS-driven NVC responses observed in the hAPP(J20) model of AD.

In contrast to the pronounced decrease in the nNOS-dependent component of NVC in hAPP(J20) mice, the contribution of eNOS to NVC in this group was not significantly reduced relative to baseline (Fig. $2 E$ ) nor relative to the contribution of eNOS observed in WT mice (Fig. 2F). Thus, like for nNOS, the eNOSdependent components of NVC are absent in vehicle-treated hAPP(J20) mice. Attenuation of mTOR, however, significantly increased the magnitude of the eNOS-dependent component of NVC in rapamycin-treated hAPP(J20) mice compared with the vehicle-treated hAPP(J20) group (Fig. $2 F$ ).

Although nearly $75 \%$ of the NVC coupling response in vehicle-treated hAPP(J20) mice is not mediated by NOS (Fig. $2 F$ ), we found that the absolute contribution of non-NOS components measured as area under the curve is reduced in magnitude in vehicle-treated hAPP(J20) mice relative to WT (Fig. 2F). As for the nNOS- and eNOS-dependent components of NVC, attenuation of $\mathrm{mTOR}$ with rapamycin restored [compared with vehicletreated hAPP(J20) mice] and even enhanced (compared with WT mice) non-NOS-mediated components of NVC in rapamycin-treated hAPP(J20) mice (Fig. 2F).

Together, these data indicate that mTOR attenuation started early in $\mathrm{AD}$-like progression preserves NVC in rapamycintreated 12-month-old hAPP(J20) mice modeling AD by increasing and even enhancing the magnitude of all its measured components. Thus, our data suggest that NVC defects in hAPP(J20) mice are driven by mTOR-dependent defects in nNOS, eNOS, and non-NOS components of the response.

\section{Short-term mTOR attenuation restores nNOS-, eNOS-, and non-NOS-dependent components of the NVC response and negates established contextual memory impairments in hAPP(J20) mice modeling AD}

Interventions that may treat cognitive deficits of $\mathrm{AD}$ would have substantial translational value. To determine the efficacy of a short ( 2 month) course of mTOR attenuation started after the onset of memory deficits and NVC dysfunction (Royea et al., 2017, 2020) in hAPP(J20) mice, 10-month-old symptomatic
hAPP(J20) mice were treated with rapamycin or vehicle supplemented in the chow for 2 months and then NVC was measured. Similar to the impact of 8 months of rapamycin treatment started before the onset of contextual memory deficits, NVC impairments in 12-month-old hAPP(J20) mice were reversed by 2 months of mTOR attenuation (Fig. $3 A, D, E$ ) with comparable efficacy (Fig. 2). Evoked CBF responses in 12-month-old rapamycin-treated hAPP(J20) mice were restored compared with the vehicle-treated hAPP(J20) group, and NVC was enhanced with respect to WT littermate mice (Fig. $3 A, D, E$ ). These data indicate that established NVC deficits in symptomatic hAPP(J20) mice modeling $\mathrm{AD}$ can be negated by short-term systemic mTOR attenuation with rapamycin.

Replicating our studies of Figure 2, we found that NVC responses in this second 12-month-old experimental cohort were reduced by $37 \%$ in the presence of the nNOS-selective inhibitor L-NPA in WT mice (Fig. $3 A, D, E$ ), supporting the notion that $\sim 37-38 \%$ of NVC in 12-month-old WT mice is driven by nNOS-mediated signaling (Fig. 2D,E). Also, subsequent inhibition of all NOS activity by application of L-NPA together with LNAME further reduced evoked CBF in WT mice by $7 \%$, for an overall reduction by the combined treatment with $\mathrm{L}-\mathrm{NPA}+\mathrm{L}-$ NAME of $44 \%$ (Fig. 3D,E), indicating the magnitude of the eNOS contribution as the remaining L-NPA + L-NAME-sensitive NOS activity, in agreement to our studies of Figure 2 and prior reports (Dirnagl et al., 1994; Lindauer et al., 1999; Bonvento et al., 2000; Kitaura et al., 2007).

In contrast to WT mice, $200 \mathrm{~nm}$ L-NPA pretreatment in vehicle-treated hAPP(J20) mice did not significantly reduce NVC relative to baseline (Fig. $3 B, D, E$ ). The profound decrease in magnitude of the L-NPA-sensitive NVC component indicates that the nNOS-dependent contribution to NVC is negligible or absent at 12 months of age in vehicle-treated hAPP(J20) mice (compare Figs. 2F, 3E). The contribution of nNOS to NVC, however, was enhanced in rapamycin-treated hAPP(J20) mice compared with the vehicle-treated hAPP(J20) and WT groups (Fig. $3 B, D, E)$.

As we found in the cohort treated for 8 months (Fig. 2E,F), superfusion of L-NPA together with the pan-NOS inhibitor L-NAME in hAPP(J20) mice did not significantly reduce evoked CBF (Fig. 3D,E), indicating that eNOS-dependent contributions to NVC are impaired. Similar to treatment for 8 months (Fig. $2 F$ ), rapamycin treatment for 2 months significantly increased the magnitude of the eNOS-dependent component of NVC compared with vehicle-treated hAPP(J20) mice (Fig. 3E). Also in agreement with the studies shown in Figure 2, attenuation of mTOR for only 2 months restored (but, in contrast to 8 months of treatment), did not enhance the non-NOS-mediated components of NVC in rapamycin-treated hAPP(J20) mice relative to WT mice (Fig. 3E).

The age of onset of contextual memory impairment in our hAPP(J20) colony is $\sim 7-8$ months of age. Because NVC is mechanistically linked to neuron function, to define the impact of restoration of NVC by a 2 month course of rapamycin started in the symptomatic phase of $\mathrm{AD}$-like disease at 10 months of age on memory, we measured contextual memory using the fearconditioning paradigm. Hippocampal-dependent contextual memory impairments in 12-month-old hAPP(J20) mice relative to WT littermates (Fig. $3 F$ ) were negated by attenuation of mTOR with 2 months of rapamycin treatment such that contextual memory in this group was indistinguishable from that of WT littermates (Fig. 3F). Additionally, we found that NVC and contextual memory (Fig. 3G) were directly correlated, where 

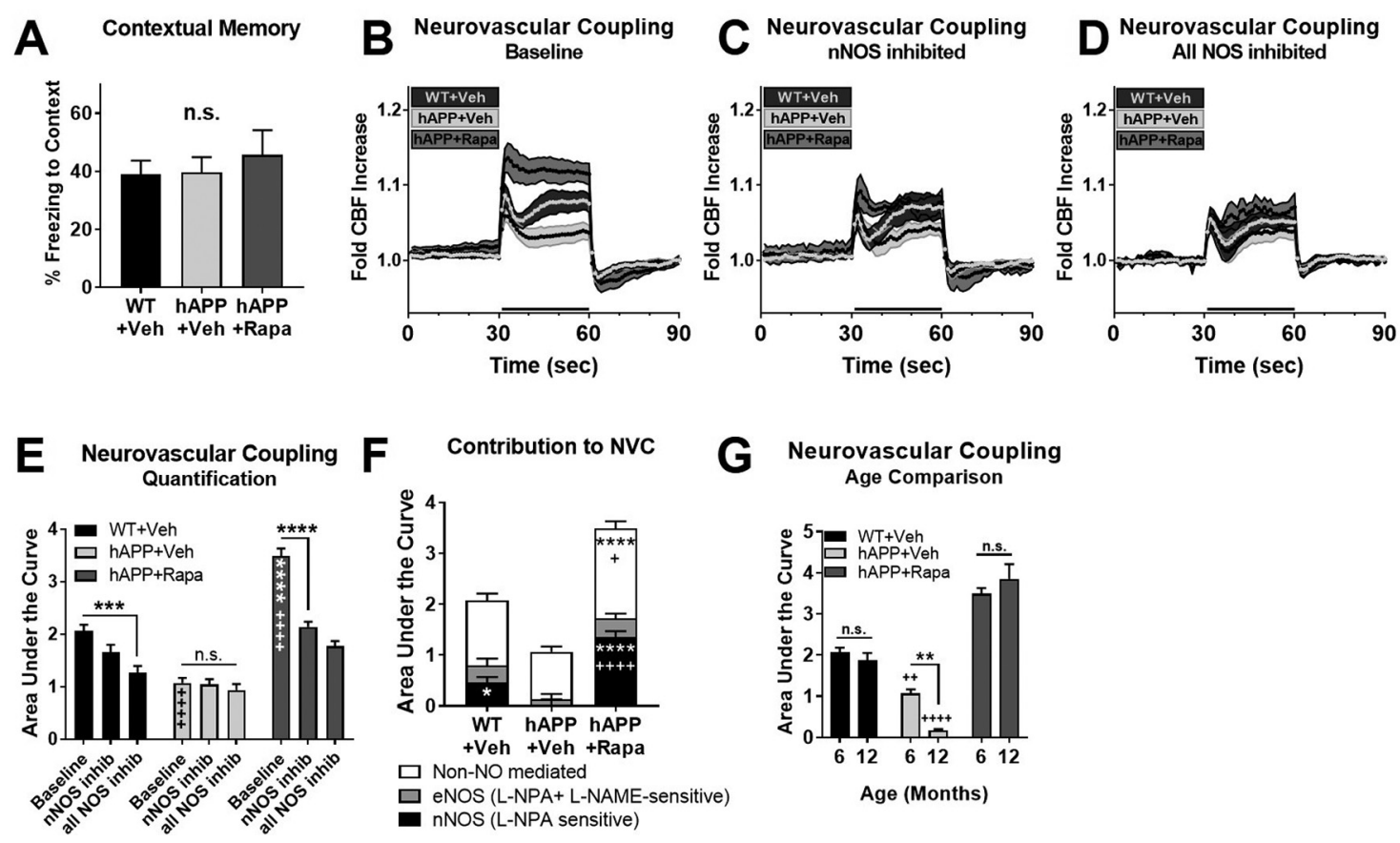

Figure 4. mTOR-driven NVC deficits precede contextual memory impairment in 6-month-old hAPP(J20) mice. A, Hippocampal-dependent contextual memory is intact in 6-month-old hAPP (J20) mice $\left(F_{(2,16)}=0.33, p=0.73\right.$, no change). $\boldsymbol{B}-\boldsymbol{D}$, Fold change in cerebral blood flow from whisker pad stimulation ( $30 \mathrm{~s}$, bold black line, representing mean \pm SEM of $\left.n=5 / \mathrm{group}\right)$ was measured sequentially in the presence of aCSF [vehicle (Veh); $\boldsymbol{B}$ ], $200 \mathrm{~nm} \mathrm{L-NPA}$ to selectively inhibit nNOS (Fig. 2A; $\boldsymbol{C}$, and $200 \mathrm{~nm} \mathrm{L-NPA+10} \mu \mathrm{m}$ L-NAME to inhibit all remaining NOS activity (i.e., eNOS; $\boldsymbol{D}$ ). $\boldsymbol{E}$, Total NVC responses during $30 \mathrm{~s}$ whisker stimulations. Area under the curve was calculated as an increase relative to baseline (i.e., only upward peaks). Baseline NVC impairment in 6-month-old hAPP(J20) mice versus WT $\left(q_{(35)}=8.71,{ }^{++++} p<0.0001\right)$ is reversed by rapamycin (Rapa) treatment $\left(2\right.$ months, $\left.q_{(35)}=21.07, * * * * p<0.0001\right)$ and NVC is enhanced in hAPP(J20)+ rapamycin compared with WT $\left(q_{(35)}=12.36,{ }^{++++} p<0.0001\right)$. A significant reduction in NVC by L-NPA superfusion $\left(q_{(35)}=11.75, * * * * p<0.0001\right)$ in the $\mathrm{hAPP}(J 20)+$ rapamycin group, which is absent in vehicle-treated $\mathrm{hAPP}(J 20)$ mice $\left(q_{(35)}=0.26, p>0.99\right)$, indicates that rapamycin restores nNOS-dependent NVC in hAPP(J20) mice. LNPA+ L-NAME-sensitive (i.e., eNOS-mediated) NVC was not significantly reduced in WT $\left(q_{(35)}=3.40, p=0.32\right)$, hAPP $(J 20)\left(q_{(35)}=0.87, p=0.99\right)$, or hAPP(J20)+ rapamycin groups $\left(q_{(35)}=\right.$ $3.04, p=0.46)$ relative to L-NPA alone. $\boldsymbol{F}$, Contributions of nNOS, eNOS, and non-NOS components to total NVC. Impaired L-NPA-sensitive, nNOS-driven NVC responses in hAPP(J20) mice $\left(q_{(35)}\right.$ $=3.67, * p=0.036)$ are negated by rapamycin $\left(2\right.$ months, $\left.q_{(35)}=11.28, * * * * p<0.0001\right)$, and the nNOS-driven NVC response is enhanced versus WT groups $\left(q_{(35)}=7.60\right.$, $\left.{ }^{++++} p<0.0001\right)$. eNOS-mediated, L-NPA+ L-NAME-sensitive NVC is unchanged at 6 months of age in all groups; mTOR attenuation enhances non-NOS-dependent NVC in rapamycin-treated hAPP(J20) mice $\left[q_{(35)}=4.27,{ }^{+} p=0.013\right.$ vs WT mice; $q_{(35)}=7.09, * * * * p<0.0001$ vs hAPP(J20) mice]. G, Progressive, early-onset NVC impairments in hAPP(J20) mice modeling AD. NVC impairments in hAPP(J20) mice are present at 6 months $\left(q_{(23)}=6.18,{ }^{++} p=0.003\right)$ and are significantly exacerbated by 12 months of age $\left(q_{(23)}=5.55, * * p=0.008\right)$. During this same time period, NVC remains unchanged in both WT animals $\left(q_{(23)}=1.17, p=0.96\right.$, not significant) and in hAPP(J20) mice treated with rapamycin $\left(q_{(23)}=2.10, p=0.67\right.$, not significant). All post hoc tests are Tukey's multiple-comparisons tests. $N=5$ mice/group except for behavioral studies ( $n=6-7 /$ group). Unless otherwise indicated, asterisks (*) in the figure represent a significant difference relative to $\mathrm{hAPP}+$ Veh and pluses $(+)$ represent a significant difference relative to $\mathrm{WT}+\mathrm{Veh}$.

increased neurovascular coupling responses were associated with better contextual memory performance $(r=0.668, p=0.009)$. This correlation also held when considering those outcomes in WT mice $(r=0.914, p=0.03$ ), highlighting the relationship between NVC and cognitive function in normative conditions. These data indicate that the restoration of NVC by only 2 months of mTOR attenuation in symptomatic animals, after the onset of memory impairment, is sufficient to negate contextual memory deficits in hAPP(J20) mice. These observations suggest that mTOR drives contextual memory impairment in hAPP (J20) mice modeling AD by inhibiting NVC.

mTOR-mediated NVC deficits emerge before the onset of contextual memory deficits in $\mathrm{hAPP}(\mathrm{J} 20)$ mice and are negated by $\mathrm{mTOR}$ attenuation

Deficits in blood flow emerge early in the pathogenesis of $\mathrm{AD}$, long before the onset of cognitive deficits (Binnewijzend et al., 2016; Iturria-Medina et al., 2016; Sweeney et al., 2018). To establish the age at which NVC deficits emerge in our cohorts of hAPP(J20) mice and define the role of mTOR, hAPP(J20) mice were treated with rapamycin-supplemented chow at 4 months of age, before the onset of contextual memory impairment (Fig. $4 A$ ), for 2 months until 6 months of age, when NVC was measured. As previously shown (Royea et al., 2017, 2020), stimulation-evoked $\mathrm{CBF}$ responses were significantly reduced in 6month-old vehicle-treated hAPP(J20) mice without contextual memory deficits (Fig. 4A) compared with WT littermates (Fig. $4 B, E$ ). Similar to the impact of long-term (Fig. 2) or short-term (Fig. 3) rapamycin treatment on older, cognitively symptomatic hAPP(J20) mice, NVC deficits in presymptomatic 6-month-old hAPP(J20) mice were negated after 2 months of mTOR attenuation with rapamycin (Fig. $4 B, E$ ). Furthermore, and as in our long-term and short-term rapamycin treatment studies (Figs. 2B, $3 A$ ), mTOR attenuation enhanced NVC responses in rapamycin-treated hAPP(J20) mice over those of WT littermate mice (Fig. 4B,E). These data indicate that NVC deficits precede contextual memory impairment in the hAPP(J20) mouse model of $\mathrm{AD}$, and that they can be negated by systemic short-term mTOR attenuation.

Inhibition of nNOS with L-NPA reduced NVC responses by $20 \%$ relative to baseline (Fig. $4 B, C, E$ ) in 6-month-old WT animals, indicating that, in contrast to $\sim 38 \%$ of the response in 12 month-old WT animals (from cohorts 1 and 2), only $20 \%$ of the NVC response is mediated by nNOS in 6-month-old WT mice. L-NPA pretreatment did not significantly reduce NVC in vehicle-treated hAPP(J20) mice (Fig. 4B,C,E,F), indicating that the nNOS-dependent contribution to NVC in hAPP(J20) mice, as in 
older, symptomatic hAPP(J20) animals, is profoundly reduced or absent in cognitively presymptomatic 6-month-old hAPP (J20) mice. The contribution of nNOS to NVC, however, was restored by rapamycin treatment compared with vehicle-treated hAPP(J20) mice, and enhanced compared with WT littermates (Fig. 4C,E,F), similar to our observations in symptomatic hAPP (J20) mice after long-term or short-term rapamycin treatment (Figs. 2F, 3E).

Also, similar to our findings in older symptomatic animals (Figs. 2F, G, 3E,F), the contribution of eNOS as the non-nNOS, LNAME-sensitive component of NVC was not significantly reduced in 6-month-old hAPP(J20) mice (Fig. 4D-F). In contrast to the impact of mTOR attenuation in 12-month-old symptomatic animals, mTOR attenuation did not have a significant impact on the eNOS-dependent component of NVC in 6month-old hAPP(J20) mice (Fig. 4D-F). Non-NO-dependent components of NVC were not significantly reduced in presymptomatic 6-month-old vehicle-treated hAPP(J20) animals, suggesting that early NVC deficits in the hAPP(J20) mouse model are driven exclusively by an impairment in nNOS. On the other hand, as in 12-month-old rapamycin-treated groups, the nonNO-mediated NVC response was restored compared with vehicle-treated animals, and enhanced compared with WT mice in rapamycin-treated presymptomatic hAPP(J20) mice (Fig. 4F).

To compare the progression of NVC impairments between our 6- and 12-month-old cohorts that were treated short term (2 months) with rapamycin, we plotted values for baseline NVC responses at both ages for each of the three treatment groups (Fig. 4G). NVC responses were not different among 6- and 12month-old WT animals. NVC impairments at 6 months, however, increased in magnitude with age in hAPP(J20) animals, evidenced by significantly more severe NVC deficits in 12-monthold relative to 6-month-old hAPP(J20) mice (Fig. 4G). A comparison of rapamycin-treated hAPP(J20) groups revealed that mTOR attenuation restores and enhances NVC to the same extent in 6- and 12-month-old hAPP(J20) groups (Fig. 4G).

\section{mTOR decreases nNOS abundance and inhibits nNOS phosphorylation at its primary activation site in cultured neuronal cells}

It was previously shown that nNOS-expressing neurons are selectively lost in entorhinal cortex and hippocampus in $\mathrm{AD}$ (Thorns et al., 1998). To define changes in nNOS expression in human $\mathrm{AD}$ across stages of disease progression, we used tissue from Braak stages III-VI, which represent intermediate and advanced tau pathology. We found that nNOS expression significantly decreases as Braak pathology increases in the hippocampal formation (Fig. 5A,B). These data suggest that overall nNOS levels decrease in hippocampal formation during $\mathrm{AD}$ pathogenesis. To define the potential role of mTOR and to define whether changes in nNOS expression observed in AD hippocampal formation are recapitulated in the microvasculature of hAPP(J20) mice, we measured nNOS expression in microvasculature isolated from 6- and 12-month-old experimental cohorts treated with 2 months of rapamycin (Fig. 5C,D). Purified microvascular fractions capture neurons closely associated with the vasculature, which include prominently interneurons directly involved in the regulation of NVC through NO release (Cauli et al., 2004). Similar to nNOS in human hippocampal formation, and, in contrast to the level of eNOS (Fig. 5C,E), we found that nNOS was significantly decreased in the microvasculature of 6-month-old hAPP(J20) mice and that this decrease was negated by $\mathrm{mTOR}$ inhibition in hAPP(J20) mice treated with rapamycin
(Fig. 5C,D). Despite showing similar decreases in magnitude in the nNOS-dependent component of NVC (Figs. 2F, 3E), and in contrast to the progressive loss of overall nNOS abundance observed in $\mathrm{AD}$ brain (Fig. $5 A, B$ ), levels of nNOS were not significantly decreased in brain microvasculature of 12-month-old hAPP(J20) mice compared with WT littermates (Fig. 5C,D). This discrepancy may arise from the fact that our measures of nNOS abundance in human hippocampal formation (Fig. $5 A, B$ ) reflect the levels of nNOS in all neurons in the sample, not just those associated with microvasculature. Immunohistochemistry studies of nNOS in neurons associated with microvasculature in human brain could not be performed because conditions effective for both immunoreactions could not be identified. Thus, whether levels of nNOS in human hippocampal formation (Fig. $5 A, B)$ reflect nNOS levels in microvascular interneurons cannot be ascertained from our data.

Together, our data suggest that nNOS depletion emerges early during $\mathrm{AD}$ pathogenesis and during $\mathrm{AD}$-like progression in the hAPP(J20) model of AD. While we could not ascertain levels of nNOS in nNOS-expressing interneurons associated with microvasculature in $\mathrm{AD}$ brain, our data suggest that an early decrease in nNOS abundance in microvasculature-associated neurons affected by ongoing $\mathrm{AD}$-like processes in hAPP(J20) mice may trigger a compensatory response that upregulates $\mathrm{nNOS}$ in $\mathrm{mi}-$ crovascular interneurons during $\mathrm{AD}$-like progression (Fig. $5 \mathrm{C}$, $D)$, but that this response does not suffice to restore function (Figs. 2B, 3A). Impairment of the nNOS-dependent component of NVC in hAPP(J20) mice at later stages of AD-like disease (Figs. 2B, 3A) may thus arise from defects in nNOS activation.

\section{mTOR inhibits nNOS phosphorylation in cultured neuronal cells}

Our data (Figs. $2 F, 3 E, 4 F$ ) indicate that mTOR inhibits nNOS function during NVC in $\mathrm{hAPP}(\mathrm{J} 20)$ mice, and that this deficit occurs early in the etiology of neurovascular uncoupling in this model of $\mathrm{AD}$ (Fig. $4 F$ ). To better understand the mechanisms by which mTOR inhibits nNOS, we used cultured N2a cells treated with vehicle or with $5.5 \mathrm{~nm}$ rapamycin, a concentration equal to blood rapamycin levels measured in mice and rats fed with $14 \mathrm{ppm}$ microencapsulated rapamycin supplemented in the chow (Harrison et al., 2009; Wilkinson et al., 2012; Fok et al., 2014; Jahrling et al., 2018; Van Skike et al., 2020). Rapamycin significantly inhibited mTOR activity in N2a cells, as indicated by an $\sim 80 \%$ decrease in levels of phosphorylated rpS6, a downstream effector of mTOR (Fig. $5 F, G)$. This decrease in mTOR activity was associated with a significant increase in the phosphorylation of $\mathrm{nNOS}$ at its activation site, Ser1412 (Fig. 5F,H), as well as in total nNOS levels (Fig. 5F,I), suggesting that mTOR impacts overall nNOS activity both by inhibiting its activation and by reducing overall levels of the enzyme in neuronal cells. In addition, mTOR attenuation upregulated Hsp90 (Fig. $5 F, J)$, a chaperone protein that is required for full activation of both nNOS and eNOS (García-Cardeña et al., 1998; Pritchard et al., 2001; Song et al., 2002) and thus has an indirect role in the regulation of both neuronal- and endothelium-mediated cerebrovascular responses (García-Cardeña et al., 1998). Together, these data suggest that mTOR attenuation may preserve NVC by concomitantly relieving mTOR-mediated inhibition and downregulation of nNOS and by relieving mTOR-mediated downregulation of Hsp90

\section{mTOR attenuation decreases $A \beta$ burden in somatosensory cortex of hAPP(J20) mice}

We and others previously showed that chronic mTOR attenuation preserves cerebrovascular integrity and function, restores memory, and diminishes A $\beta$ levels and deposition in hAPP(J20) 

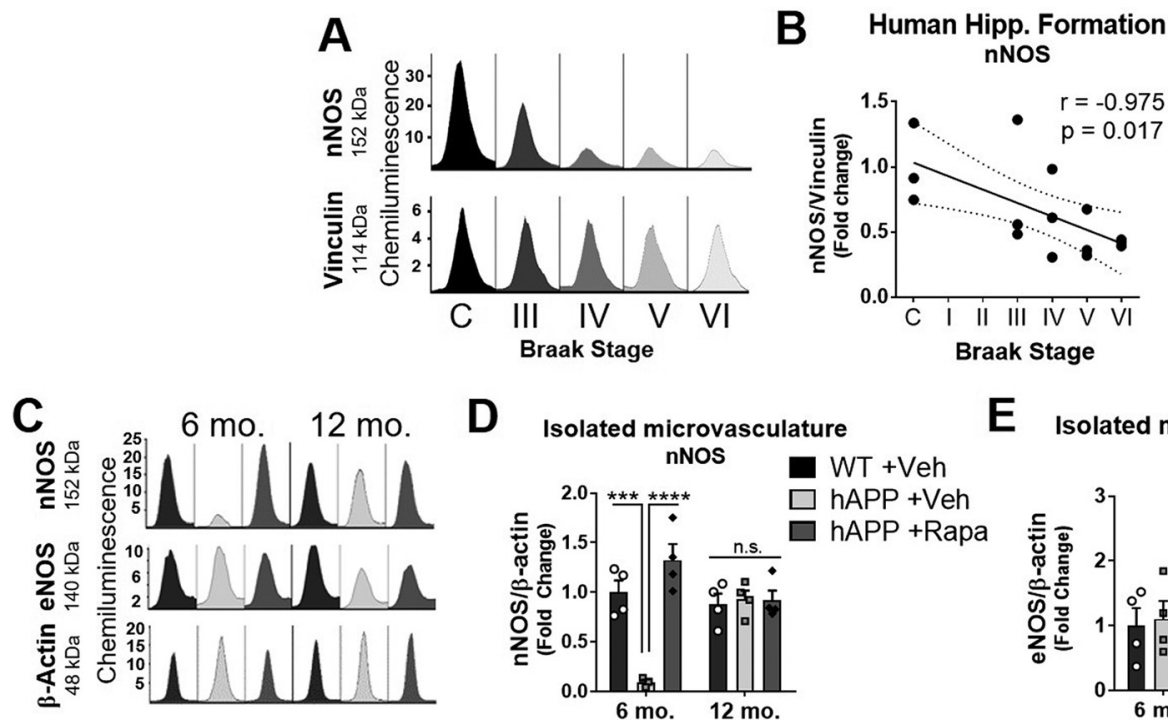

D Isolated microvasculature
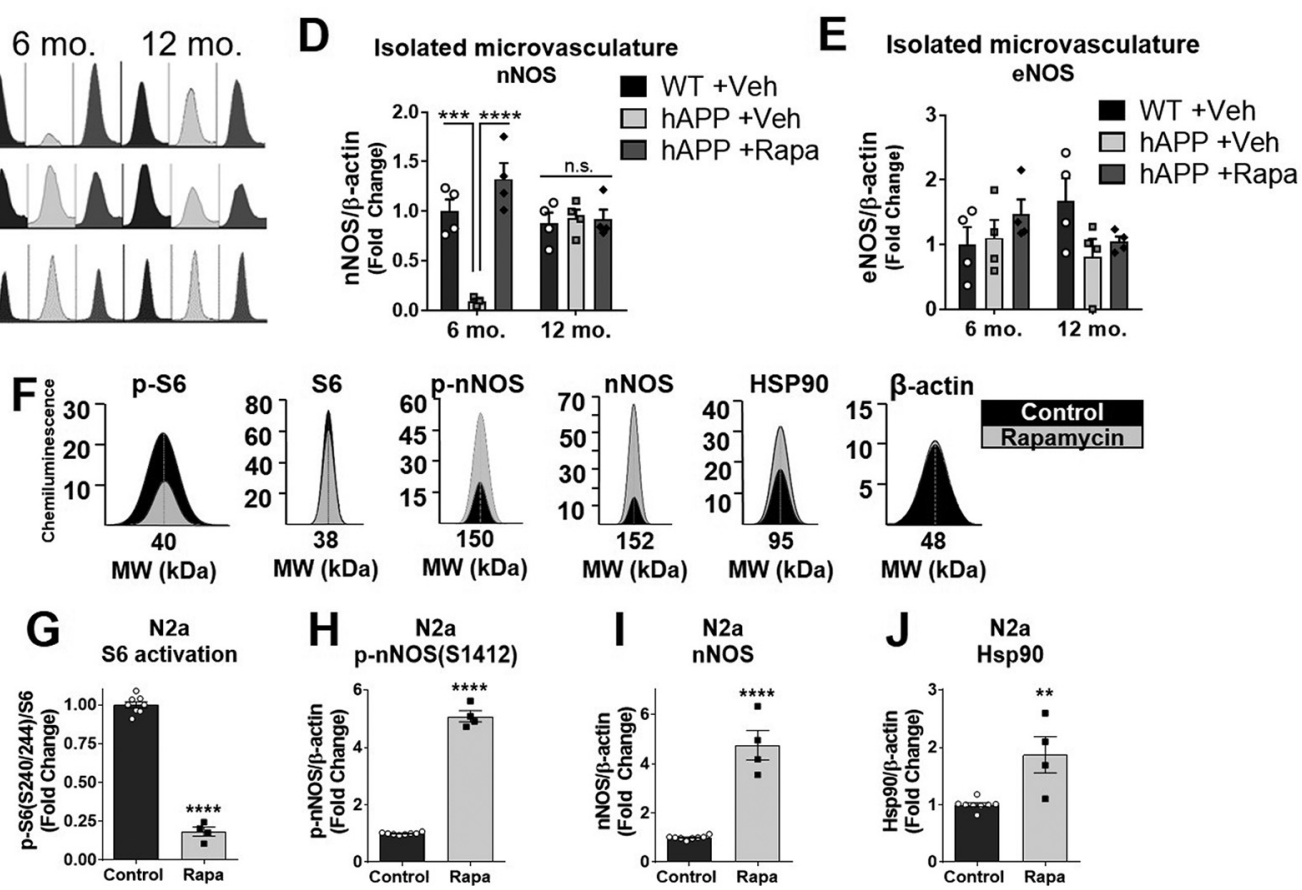

Figure 5. mTOR decreases nNOS abundance and inhibits nNOS phosphorylation at its primary activation site in cultured neuronal cells. A, Representative electropherograms of chemiluminescent signals detected by capillary Western immunoassay (Wes; Beekman et al., 2018) measuring total nNOS from hippocampal formation of patients at Braak stages III-VI compared with nonAD controls (C). B, Quantitative analysis shows decreased nNOS abundance in the hippocampal formation with progression of Braak pathology (Spearman's $r=-0.975, p=0.02)$. Data are a scatter plot overlaid with the regression line and $95 \% \mathrm{Cl}$ representing $n=3 /$ group. C, Representative electropherograms of chemiluminescent signals detected by capillary Wes measuring total nNOS (152 kDa), eNOS (140 kDa), and $\beta$-actin (48 kDa) in isolated microvasculature from hAPP(J20) mice at 6 or 12 months (mo.) of age that received 2 months of vehicle (Veh) or rapamycin (Rapa)-containing diets. D, Total nNOS is reduced in 6-month-old hAPP(J20) mice modeling early-stage preclinical AD (Sidak's test, $\left.t_{(17)}=5.42, p=0.0001\right)$. Two months of mTOR attenuation restored nNOS expression in hAPP(J20) mice treated with rapamycin (Sidak's test, $\left.t_{(17)}=7.37, p<0.0001\right)$. No change in total nNOS was observed in 12-month-old hAPP(J20) mice. $\boldsymbol{E}$, Total eNOS protein expression is unchanged by age $\left(F_{(2,18)}=0.005, p=0.94\right)$, treatment $\left(F_{(2,18)}=1.19, p=0.33\right)$, or their interaction $\left(F_{(2,18)}=2.67, p=0.10\right)$. $\boldsymbol{F}$, Representative electropherograms of chemiluminescent signals detected by capillary Wes in lysates from N2a cells. $\mathbf{G}-J$, Quantitative analyses of data in $\boldsymbol{F}$ indicate that rapamycin (5.5 nM) treatment inhibits mTOR in N2a cells $\left(81.7 \%\right.$ reduction in $\mathbf{S 6}$ phosphorylation, $\left.t_{(10)}=23.5, * * * * p<0.0001 ; \boldsymbol{G}\right)$; increases $n N 0 S$ Ser1412 phosphorylation $\left(t_{(10)}=31.2, * * * * p<0.0001 ; \boldsymbol{H}\right)$ and total nNOS levels $\left(t_{(14)}=9.3\right.$, $* * * * p<0.0001$; $I$; and increases Hsp90 levels $\left(t_{(10)}=4.0, * * p=0.003\right)$ in N2a cells ( $)$. Data are scatter plots for $n=8$ controls and $n=4$ rapamycin-treated N2a cultures, from $n=4$ independent experiments performed on different days, overlaid on a bar graph representing mean $\pm \mathrm{SEM}$.

mice and other AD models (Spilman et al., 2010; Lin et al., 2013; Caccamo et al., 2014; Van Skike et al., 2018). Thus, we next sought to define whether the restoration of cortical NVC by a relatively short 2 month course of mTOR attenuation with rapamycin (Figs. 3-4) was associated with changes in overall $\mathrm{A} \beta$ levels and $\mathrm{A} \beta$ deposition in somatosensory cortex of our 6 - and 12month-old experimental groups of hAPP(J20) mice. As previously shown (Hsia et al., 1999; Mucke et al., 2000), cortical A $\beta$ deposition increased with age in vehicle-treated hAPP(J20) mice (Fig. 6A,B). In agreement with prior studies (Spilman et al., 2010; Lin et al., 2013; Caccamo et al., 2014), the A $\beta$ load at 12 months of age was significantly reduced in hAPP(J20) mice treated with rapamycin (Fig. 6A,B), and this difference was also observed as a trend that did not reach statistical significance in 6-month-old rapamycin-treated hAPP(20) mice. While both $\mathrm{A} \beta_{42}$ and $\mathrm{A} \beta_{40}$ increased with age in cortex of vehicle-treated hAPP(J20) animals (Fig. 6C,D), as shown previously (Spilman et al., 2010) levels of the more aggregation-prone $\mathrm{A} \beta_{42}$ (Fig. 6C), but not levels of $\mathrm{A} \beta_{40}$ (Fig. $6 D$ ), were reduced in rapamycin-treated hAPP (J20) mice. Thus, the restoration of NVC in barrel cortex by mTOR attenuation in rapamycin-treated hAPP $(J 20)$ mice is associated with significantly reduced $\mathrm{A} \beta_{42}$ levels in this brain region.

\section{Discussion}

Cerebrovascular dysfunction, a central driver of $\mathrm{AD}$ pathogenesis (Girouard and Iadecola, 2006; Lecrux and Hamel, 2011; Zlokovic, 2011; Kisler et al., 2017), is recapitulated in various models of AD amyloidopathy (Merlini et al., 2011; Winkler et al., 2015; Klakotskaia et al., 2018), including hAPP(J20) mice (Nicolakakis et al., 2008; Tong et al., 2009; Lin et al., 2013; Ongali et al., 2014; Royea et al., 2017, 2020; Van Skike et al., 2018), in models of tauopathy (Bennett et al., 2018; de Jong and Jepps, 2018) and in models recapitulating combined AD pathologies 


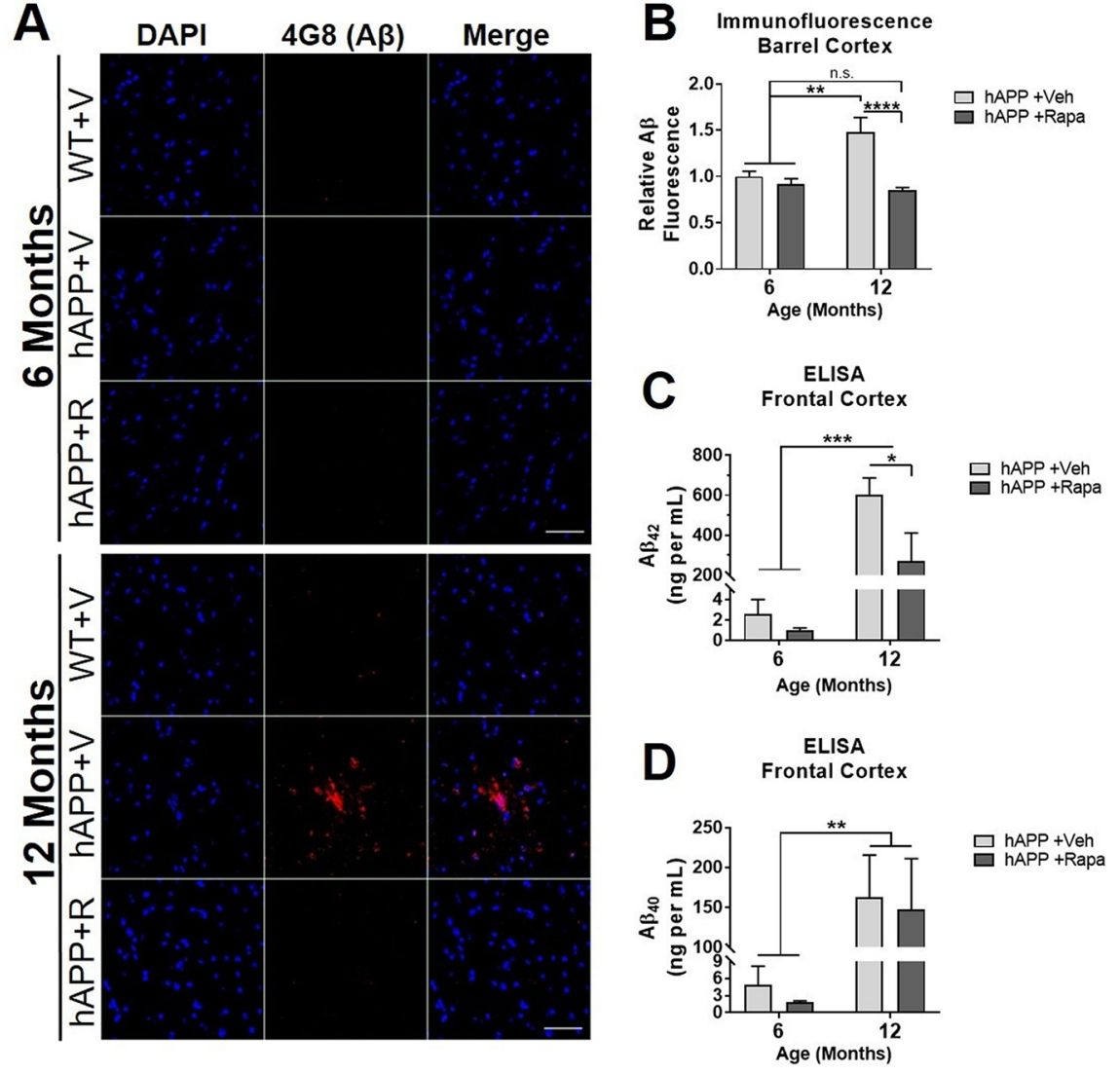

Figure 6. mTOR drives $A \beta$ accumulation in somatosensory cortex of hAPP(J20) mice. $\boldsymbol{A}$, Representative images of $\mathrm{A} \beta$ immunofluorescence in whisker barrel cortex of 6 - and 12-month-old hAPP(J20) mice. $\boldsymbol{B}$, Analysis of data in $\boldsymbol{A}$ shows that the significant increase in A $\beta$ immunoreactivity in barrel cortex of 12-month-old versus 6-month-old hAPP(J20) mice $\left(q_{(44)}\right.$ $=5.43, * * p=0.002$ ) is abolished by 2 months of mTOR attenuation with rapamycin (Rapa; $q_{(44)}=7.14, * * * * p<0.0001$, $\mathrm{hAPP}+$ rapamycin vs hAPP + vehicle (Veh) at 12 months of age), decreasing to levels indistinguishable from 6-month-old $\operatorname{hAPP}(J 20)$ mice $\left(q_{(44)}=1.71, p=0.62\right)$. Immunofluorescent $\mathrm{A} \beta$ readings were taken from three individual, randomly chosen fields of view within the barrel cortex of $n=4$ animals/group. $\boldsymbol{C}, \boldsymbol{D}$, The age-related increase in $\mathrm{A} \beta_{42}$ levels from frontal cortex of hAPP(J20) mice $\left(q_{(13)}=7.64, * * * p=0.0006\right)$ is significantly attenuated by rapamycin treatment $\left(q_{(13)}=4.23\right.$, $* p=0.04$ ), but rapamycin treatment does not alter $\mathrm{A} \beta_{40}$ levels (main effect of age: $F_{(1,13)}=15.42, * * p=0.001$ ). For ELISA readings $(\boldsymbol{C}, \boldsymbol{D}), n=3-5 /$ group. For all panels, data represent the mean \pm SEM and post hoc tests are Tukey's multiple-comparisons tests.

(Joo et al., 2017; Lourenço et al., 2017). Although nNOS and non-NOS components of NVC were significantly and progressively impaired in hAPP(J20) mice (Figs. 2-4), the progression of $\mathrm{AD}$-like disease in this model was accompanied by consistently diminished nNOS-dependent contributions to the evoked CBF response (Figs. 2-4). The principal source of NO during the NVC response is from GABAergic interneurons closely juxtaposed to vasculature (Cauli et al., 2004; Kocharyan et al., 2008). FAD-mutant APP is overexpressed in all neuron types in hAPP (J20) mice, including microvascular interneurons. Thus, it is possible that reduced signaling from lost or impaired GABAergic interneurons that are critical for full expression of the NVC response (Cauli et al., 2004; Kocharyan et al., 2008) may at least partially underlie decreased NVC responses in this model of AD. Moreover, synaptic deficits (including loss of presynaptic density) emerge early (3-4 weeks of age) in hAPP(J20) mice (Hsia et al., 1999; Mucke et al., 2000; Galvan et al., 2006; Saganich et al., 2006; Harris et al., 2010). Thus, in addition to loss or impairment of vasculature-associated GABAergic interneurons, a loss or deficit in the activation of principal glutamatergic neurons that mediate somatosensory responses through NO release (Garthwaite and Boulton, 1995) may also contribute to decreased $\mathrm{NVC}$ responses in the hAPP(J20) model of $\mathrm{AD}$. Of note, cerebrovascular deficits in hAPP(J20) mice are not driven by altered glucose metabolism, since rates of glucose consumption are unaffected by $\mathrm{AD}$-like disease in latestage symptomatic hAPP(J20) mice compared with WT animals (Lin et al., 2013).

In partial agreement with our observations, prior studies showed lower numbers of reactive blood vessels without changes in blood vessel diameter following stimulation of neocortical interneurons that release NO (Cauli et al., 2004) in the APP/ PS1 model of AD compared with WT mice (Rancillac et al., 2012), suggesting a failure of neuronal signaling rather than a vascular dysfunction in APP/PS1 mice. On the other hand, neurovascular uncoupling in 3xTg-AD mice modeling $\mathrm{AD}$ is driven by a diminished vascular response to an unchanged NO signal relative to WT mice (Lourenço et al., 2017), which suggests a vascular etiology for impaired NVC in this model.

The involvement of dysregulated mTOR in AD (Caccamo et al., 2014; Sun et al., 2014; Tramutola et al., 2015; Di Domenico et al., 2017) is recapitulated in diverse AD models of amyloidopathy and tauopathy (Spilman et al., 2010; Ozcelik et al., 2013; Caccamo et al., 2014; Siman et al., 2015; Lin et al., 2017). Previous research has shown that mTOR signaling is inhibited in peripheral tissues including heart, liver, kidney, and fat of mice fed a diet containing microencapsulated rapamycin that was used for our studies (Harrison et al., 2009; Zhang et al., 2014). We (Spilman et al., 2010; Halloran et al., 2012) and others (Caccamo et al., 2010) found that administration of rapamycin supplemented in chow attenuates mTOR activity in brain by $\sim 30-35 \%$. We previously identified mTOR as a critical mediator of cerebrovascular dysfunction in several independent models of $\mathrm{AD}$, including hAPP(J20) mice (Spilman et al., 2010; Lin et al., 2013, 2017; Van Skike et al., 2018), a model of vascular cognitive impairment (Jahrling et al., 2018; Van Skike et al., 2018) and in normative aging in rats (Van Skike et al., 2020). Preservation of cerebral blood flow and vascular integrity by mTOR attenuation in hAPP (J20) mice depends on the restoration of NOS activity (Lin et al., 2013). This indicates that mTOR drives resting CBF deficits in this model, at least in part, through the inhibition of NOS. In addition to impaired CBF, hAPP(J20) mice show profound NVC deficits (Nicolakakis et al., 2008; Tong et al., 2009; Ongali et al., 2014; Royea et al., 2017). Because nNOS has an important role in NVC (Dirnagl et al., 1993; Cholet et al., 1996) and recent studies have also suggested a potential role of eNOS in the response (Chen et al., 2014; Toth et al., 2015), we sought to define whether mTOR-dependent inhibition of NOS drives NVC impairments in the hAPP(J20) model of AD. Consistent with previously published studies (Nicolakakis et al., 2008; Tong et al., 2009; Ongali et al., 2014; Royea et al., 2017), we found profound NVC impairments in hAPP(J20) mice that precede the onset of contextual 


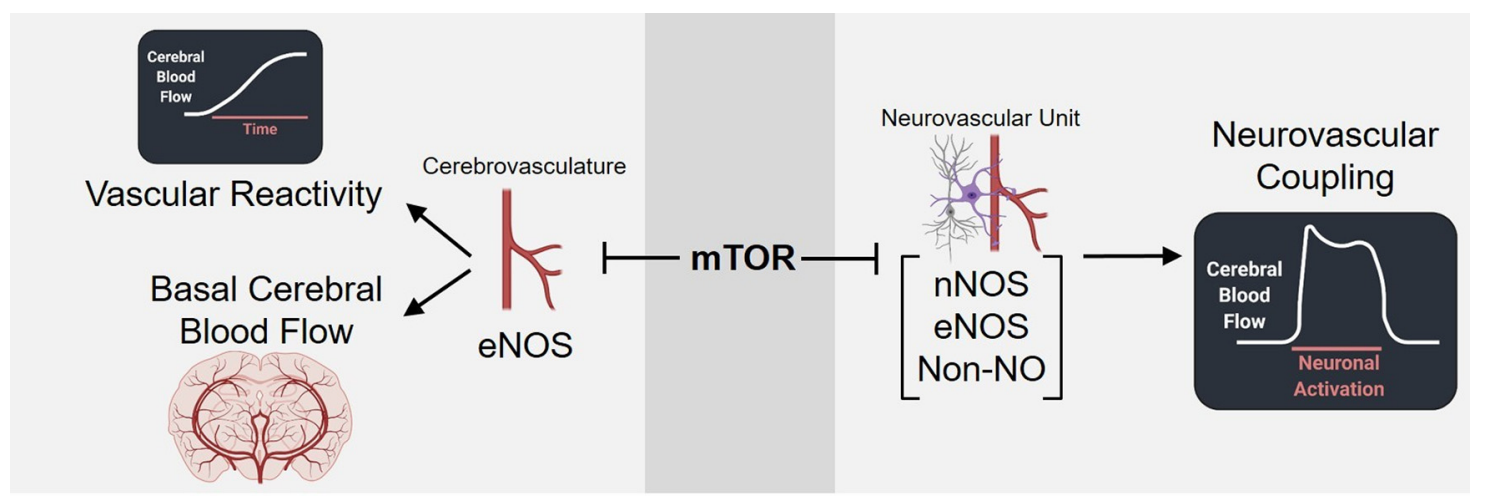

Figure 7. mTOR-dependent regulation of cerebrovascular function through nitric oxide synthases. mTOR inhibits neurovascular coupling through the regulation of nNOS-, eNOS-, and nonNO-dependent components of the neurovascular coupling response. Our prior studies indicate that mTOR drives cerebrovascular reactivity deficits and reduced baseline cerebral blood flow through the inhibition of eNOS activity (Van Skike and Galvan, 2018) in models of AD ( Lin et al., 2013, 2017; Van Skike et al., 2018), in models of vascular cognitive impairment (Jahrling et al., 2018; Van Skike et al., 2018), and in normative aging (Van Skike et al., 2020). Figure created in part with BioRender.

memory impairment. We show that mTOR drives progressive NVC deficits, evident as early as 6 months of age (Fig. $4 G$ ), consistent with the early emergence of cerebrovascular deficits in AD (Iturria-Medina et al., 2016). Although spatial learning and memory deficits before 6 months of age have been reported (Cheng et al., 2007; Wright et al., 2013; Royea et al., 2020), contextual fear-conditioned memory was intact in hAPP(J20) mice at 6 months of age, and mTOR inhibition had no impact on this outcome (Fig. 4A)

Our data points to an early emergence of nNOS dysfunction in $\mathrm{AD}$ (Fig. $5 A-D$ ) and indicates that mTOR mediates nNOS inhibition early in the etiology of neurovascular uncoupling in the hAPP(J20) AD model (Fig. 4). Further, our data show that mTOR also inhibits non-NOS-dependent components of NVC early in AD-like progression (Figs. $2 F, 3 E, 4 F$ ). We showed that the inhibition of mTOR enhances eNOS activity during NVC in 12-month-old hAPP(J20) mice treated with rapamycin, but this facilitation only emerged in later $\mathrm{AD}$-like progression (Figs. $2 F$, $3 E)$. mTOR-dependent nNOS inhibition, however, drove the largest loss of activity-evoked $\mathrm{CBF}$ in hAPP(J20) mice at all stages of AD-like progression (Figs. $2 F, 3 E, 4 F$ ). Consistent with these observations, mTOR attenuation restored expression of nNOS in neurons associated with brain microvasculature in 6month-old hAPP(J20) mice treated with rapamycin (Fig. 5C,D). Of note, we found no change in nNOS abundance in microvascular fractions purified from hAPP(J20) mice at 12 months of age. This could be explained by activation of a compensatory response to the dysregulation of nNOS production in neurons affected by $\mathrm{AD}$-like processes in more severe stages of $\mathrm{AD}$-like disease in hAPP(J20) mice.

Attenuation of mTOR with rapamycin was sufficient to increase nNOS activation in cultured neuronal cells (Fig. 5G-I). The restoration of NVC in hAPP(J20) mice was associated with the negation of established contextual memory deficits in 12month-old mice (Fig. 3F), but enhancement of the NVC response in hAPP(J20) animals via rapamycin treatment (Figs. $2 B, 3 A, 4 B)$ did not impact memory in cognitively presymptomatic 6-month-old hAPP(J20) animals (Fig. 4A) and did not confer additional cognitive benefits above those of WT when cognitively symptomatic 12-month-old hAPP(J20) animals were treated with rapamycin (Fig. $3 F$ ). Although NVC was only measured in somatosensory cortex, the preservation of NVC by systemic mTOR attenuation (Figs. 2-4) likely extends to other brain regions such as hippocampus, thereby contributing to the maintenance of hippocampal-dependent cognitive function in rapamycin-treated $\mathrm{AD}$ mice (Fig. $3 F$ ). To this point, we demonstrated that the magnitude of the NVC response was directly correlated with contextual memory performance in 12-month-old mice (Fig. $3 G$ ), suggesting preservation of NVC in multiple brain regions driven by systemic mTOR attenuation. Additionally, the positive correlation between NVC responses and contextual memory performance was also observed in WT animals, suggesting that NVC is strongly tied to cognitive performance under normative conditions.

Nitric oxide is released by interneurons closely associated with vasculature during NVC (Cauli et al., 2004) and can also be released by principal cortical glutamatergic neurons whose activity triggers the hyperemic response (Faraci and Breese, 1993; Garthwaite and Boulton, 1995; Buerk et al., 2003). Our results thus suggest that mTOR activity inhibits nNOS in vascular interneurons, in principal glutamatergic cortical neurons, or both. Moreover, because the magnitude of the NVC response is linked to the magnitude of principal neuron activation during stimulation, the robust enhancement of the NVC response at all stages of AD-like disease in hAPP(J20) mice by mTOR attenuation may reflect the additive relief of mTOR-mediated inhibition of nNOS both in perivascular interneurons and in principal glutamatergic neurons of the somatosensory cortex. This interaction may be further compounded with relief of other mTOR-driven mechanisms of AD toxicity that directly impact neurons and vasculature, including the inhibition of autophagy and attendant increase in levels of misfolded pathogenic A $\beta$ (Spilman et al., 2010; Majumder et al., 2011; Lin et al., 2013; Caccamo et al., 2014). Indeed, neuronal dysfunction precedes the sharp increases in $\mathrm{A} \beta$ levels in hAPP(J20) mice (Hsia et al., 1999; Mucke et al., 2000; Saganich et al., 2006), thus impaired neuronal activity is expected in hAPP(J20) mice at all ages examined in our studies. Although it is possible that cortical principal neuron dysfunction in hAPP(J20) mice could be masked by the robust restoration of nNOS activity during NVC by rapamycin, our results suggest that the attenuation of mTOR may restore cortical glutamatergic neuron function. The enhancement of the NVC response in rapamycin-treated hAPP(J20) mice may thus be explained by the combined impact of relieving $\mathrm{mTOR}$-driven mechanisms of disease at several sites of mTOR action. Direct measures of cortical neuron function should clarify the potential role of improved somatosensory neuron function in the restoration of NVC by rapamycin in hAPP(J20) mice. 
We have previously shown that mTOR drives cerebrovascular dysfunction through the inhibition of eNOS activity (Van Skike and Galvan, 2018) in models of AD (Lin et al., 2013, 2017; Van Skike et al., 2018), in models of vascular cognitive impairment (Jahrling et al., 2018; Van Skike et al., 2018), and in normative aging (Van Skike et al., 2020). Further, these studies demonstrated that the restoration of resting $\mathrm{CBF}$ in $\mathrm{AD}$ model mice by mTOR attenuation is critically dependent on the restoration of eNOS function (Lin et al., 2013). Recent studies have suggested a potential role of eNOS in the NVC response (Chen et al., 2014; Toth et al., 2015), which we confirmed in the present studies through serial application of NOS inhibitors (Fig. 2A-D). While we did not detect a failure of eNOS signaling during NVC in hAPP(J20) mice, it is possible that our NVC readouts are not sensitive enough to discern changes in eNOS activity, which is of very low absolute magnitude. However, consistent with our previous studies (Lin et al., 2013, 2017; Van Skike et al., 2018), our data indicate that both short ( 2 months) and long ( 8 months) treatment durations of rapamycin enhance the eNOS contribution to NVC in 12-month-old hAPP(J20) mice (Figs. 2F, 3E) but not in younger hAPP(J20) mice at 6 months of age (Fig. $4 F$ ). This age-dependent restoration of eNOS activation in hAPP(J20) mice treated with rapamycin may arise from the activation of additional compensatory mechanisms that restore the NVC response in more advanced stages of $\mathrm{AD}$-like disease in mice.

Additionally, future studies should consider a potential role of iNOS in cerebrovascular function. While the direct contribution of iNOS to NVC is not defined and not expected because of fundamental differences in mechanisms of regulation of iNOS compared with nNOS and eNOS (i.e., expression when induced compared with constitutive expression, respectively), NO derived from iNOS may impact NVC negatively through mechanisms involving neuroinflammation. Specifically, iNOS expression is increased in microglia and astrocytes in AD (Vodovotz et al., 1996; Wallace et al., 1997), producing elevated levels of NO and peroxynitrite through the NO-superoxide pathway (Wallace et al., 1997; Nathan et al., 2005). Although iNOS-derived NO is typically associated with neurotoxicity in AD (Iadecola et al., 1995; Nathan et al., 2005), iNOS expression has been found in cerebrovascular smooth muscle cells after traumatic brain injury (Nathan et al., 2005). Further studies are needed to define the role of iNOS in NVC dysfunction associated with chronic disease states such as AD.

While $\mathrm{A} \beta_{40}$ preferentially accumulates in fibrillar vascular lesions and has been implicated in vascular dysfunction in $\mathrm{AD}$ (Bell and Zlokovic, 2009; Ghiso et al., 2014; Parodi-Rullán et al., 2019), our data suggest that mTOR also contributes to $\mathrm{A} \beta_{42}$ accumulation (Fig. 6), since we have previously shown that mTOR attenuation both increases $\mathrm{A} \beta$ clearance through the restoration of cerebrovascular integrity and function (Lin et al., 2013) and through the induction of autophagy (Spilman et al., 2010). These observations are in agreement with prior studies in hAPP(J20) mice (Spilman et al., 2010; Lin et al., 2013), and align with previous data from other models of $\mathrm{AD}$ amyloidopathy (Caccamo et al., 2014) and combined AD-like tau and amyloid pathology (Majumder et al., 2011). Additionally, these data indicate that nNOS dysfunction emerges early in the pathogenesis of $\mathrm{AD}$, before the presence of $\mathrm{A} \beta$ (Figs. $4,5 C, D, 6 A, B ; 6$ months of age) and neurofibrillary tangle pathology (Fig. $5 A, B$ ) within the brain region measured.

The present studies, together with our previous work, identify mTOR as a critical driver of NVC impairment in a model of AD through the inhibition of $\mathrm{nNOS}$ and non-NOS-dependent components of NVC (Fig. 7). Our studies show that mTOR attenuation can both prevent and reverse NVC deficits and attendant AD-like memory deficits, suggesting that mTOR inhibitors, available in the clinic, have tangible potential for the prevention and/or treatment of AD. Since cerebrovascular dysfunction emerges at the earliest stages of $\mathrm{AD}$, restoration of brain vascular function with rapamycin may delay onset and/or slow disease progression in $\mathrm{AD}$ and potentially other age-associated dementias.

\section{References}

Almeida J, Oliveira LA, Benini R, Crestani CC (2019) Differential roles of hippocampal nNOS and iNOS in the control of baroreflex function in conscious rats. Brain Res 1710:109-116.

Attwell D, Buchan AM, Charpak S, Lauritzen M, Macvicar BA, Newman EA (2010) Glial and neuronal control of brain blood flow. Nature 468:232243.

Ayajiki K, Fujioka H, Okamura T, Toda N (2001) Relatively selective neuronal nitric oxide synthase inhibition by 7-nitroindazole in monkey isolated cerebral arteries. Eur J Pharmacol 423:179-183.

Banwait S, Galvan V, Zhang J, Gorostiza OF, Ataie M, Huang W, Crippen D, Koo EH, Bredesen DE (2008) C-terminal cleavage of the amyloid- $\beta$ protein precursor at Asp664: a switch associated with Alzheimer's disease. JAD 13:1-16.

Beamer E, Otahal J, Sills GJ, Thippeswamy T (2012) N(w)-propyl-L-arginine (L-NPA) reduces status epilepticus and early epileptogenic events in a mouse model of epilepsy: behavioural, EEG and immunohistochemical analyses. Eur J Neurosci 36:3194-3203.

Beekman C, Janson AA, Baghat A, van Deutekom JC, Datson NA (2018) Use of capillary Western immunoassay (Wes) for quantification of dystrophin levels in skeletal muscle of healthy controls and individuals with Becker and Duchenne muscular dystrophy. PLoS One 13:e0195850.

Bell RD, Zlokovic BV (2009) Neurovascular mechanisms and blood-brain barrier disorder in Alzheimer's disease. Acta Neuropathol 118:103-113.

Bennett RE, Robbins AB, Hu M, Cao X, Betensky RA, Clark T, Das S, Hyman BT (2018) Tau induces blood vessel abnormalities and angiogenesis-related gene expression in P301L transgenic mice and human Alzheimer's disease. Proc Natl Acad Sci U S A 115:E1289-E1298.

Binnewijzend MAA, Benedictus MR, Kuijer JPA, van der Flier WM, Teunissen CE, Prins ND, Wattjes MP, van Berckel BNM, Scheltens P, Barkhof F (2016) Cerebral perfusion in the predementia stages of Alzheimer's disease. Eur Radiol 26:506-514.

Bonvento G, Cholet N, Seylaz J (2000) Sustained attenuation of the cerebrovascular response to a $10 \mathrm{~min}$ whisker stimulation following neuronal nitric oxide synthase inhibition. Neurosci Res 37:163-166.

Buerk DG, Ances BM, Greenberg JH, Detre JA (2003) Temporal dynamics of brain tissue nitric oxide during functional forepaw stimulation in rats. NeuroImage 18:1-9.

Burke M, Bührle C (2006) BOLD response during uncoupling of neuronal activity and CBF. Neuroimage 32:1-8.

Caccamo A, Majumder S, Richardson A, Strong R, Oddo S (2010) Molecular interplay between mammalian target of rapamycin (mTOR), amyloidbeta, and Tau: effects on cognitive impairments. J Biol Chem 285:1310713120 .

Caccamo A, De Pinto V, Messina A, Branca C, Oddo S (2014) Genetic reduction of mammalian target of rapamycin ameliorates Alzheimer's diseaselike cognitive and pathological deficits by restoring hippocampal gene expression signature. J Neurosci 34:7988-7998.

Cauli B, Tong XK, Rancillac A, Serluca N, Lambolez B, Rossier J, Hamel E (2004) Cortical GABA interneurons in neurovascular coupling: relays for subcortical vasoactive pathways. J Neurosci 24:8940-8949.

Chen BR, Kozberg MG, Bouchard MB, Shaik MA, Hillman EMC (2014) A critical role for the vascular endothelium in functional neurovascular coupling in the brain. J Am Heart Assoc 3:e000787.

Cheng IH, Scearce-Levie K, Legleiter J, Palop JJ, Gerstein H, Bien-Ly N, Puoliväli J, Lesné S, Ashe KH, Muchowski PJ, Mucke L (2007) Accelerating amyloid-beta fibrillization reduces oligomer levels and functional deficits in Alzheimer disease mouse models. J Biol Chem 282:23818-23828. 
Cholet N, Bonvento G, Seylaz J (1996) Effect of neuronal NO synthase inhibition on the cerebral vasodilatory response to somatosensory stimulation. Brain Res 708:197-200.

Cremers CM, Knoefler D, Gates S, Martin N, Dahl JU, Lempart J, Xie L, Chapman MR, Galvan V, Southworth DR, Jakob U (2016) Polyphosphate: a conserved modifier of amyloidogenic processes. Mol Cell 63:768-780.

de Jong IEM, Jepps TA (2018) Impaired Kv7 channel function in cerebral arteries of a tauopathy mouse model (rTg4510). Physiol Rep 6:e13920.

Di Domenico F, Barone E, Perluigi M, Butterfield DA (2017) The triangle of death in Alzheimer's disease brain: the aberrant cross-talk among energy metabolism, mammalian target of rapamycin signaling, and protein homeostasis revealed by redox proteomics. Antioxid Redox Signal 26:364387.

Dirnagl U, Lindauer U, Villringer A (1993) Role of nitric oxide in the coupling of cerebral blood flow to neuronal activation in rats. Neurosci Lett 149:43-46.

Dirnagl U, Niwa K, Lindauer U, Villringer A (1994) Coupling of cerebral blood flow to neuronal activation: role of adenosine and nitric oxide. Am J Physiol 267:H296-H301.

Faraci FM, Breese KR (1993) Nitric oxide mediates vasodilatation in response to activation of N-methyl-D-aspartate receptors in brain. Circ Res 72:476-480.

Fok WC, Chen Y, Bokov A, Zhang Y, Salmon AB, Diaz V, Javors M, Wood WH 3rd, Zhang Y, Becker KG, Pérez VI, Richardson A (2014) Mice fed rapamycin have an increase in lifespan associated with major changes in the liver transcriptome. PLoS One 9:e83988.

Furchgott RF, Zawadzki JV (1980) The obligatory role of endothelial cells in the relaxation of arterial smooth muscle by acetylcholine. Nature 288:373-376.

Galvan V, Gorostiza OF, Banwait S, Ataie M, Logvinova AV, Sitaraman S, Carlson E, Sagi SA, Chevallier N, Jin K, Greenberg DA, Bredesen DE (2006) Reversal of Alzheimer's-like pathology and behavior in human APP transgenic mice by mutation of Asp664. Proc Natl Acad Sci U S A 103:7130-7135.

García-Cardeña G, Fan R, Shah V, Sorrentino R, Cirino G, Papapetropoulos A, Sessa WC (1998) Dynamic activation of endothelial nitric oxide synthase by Hsp90. Nature 392:821-824.

Garthwaite J, Boulton CL (1995) Nitric oxide signaling in the central nervous system. Annu Rev Physiol 57:683-706.

Ghiso J, Fossati S, Rostagno A (2014) Amyloidosis associated with cerebral amyloid angiopathy: cell signaling pathways elicited in cerebral endothelial cells. J Alzheimers Dis 42 [Suppl 3]: S167-S176.

Girouard H, Iadecola C (2006) Neurovascular coupling in the normal brain and in hypertension, stroke, and Alzheimer disease. J Appl Physiol (1985) 100:328-335.

Halloran J, Hussong SA, Burbank R, Podlutskaya N, Fischer KE, Sloane LB, Austad SN, Strong R, Richardson A, Hart MJ, Galvan V (2012) Chronic inhibition of mammalian target of rapamycin by rapamycin modulates cognitive and non-cognitive components of behavior throughout lifespan in mice. Neuroscience 223:102-113.

Harris JA, Devidze N, Halabisky B, Lo I, Thwin MT, Yu G-Q, Bredesen DE, Masliah E, Mucke L (2010) Many neuronal and behavioral impairments in transgenic mouse models of Alzheimer's disease are independent of caspase cleavage of the amyloid precursor protein. J Neurosci 30:372381.

Harrison DE, Strong R, Sharp ZD, Nelson JF, Astle CM, Flurkey K, Nadon NL, Wilkinson JE, Frenkel K, Carter CS, Pahor M, Javors MA, Fernandez E, Miller RA (2009) Rapamycin fed late in life extends lifespan in genetically heterogeneous mice. Nature 460:392-395.

Hays CC, Zlatar ZZ, Wierenga CE (2016) The utility of cerebral blood flow as a biomarker of preclinical alzheimer's disease. Cell Mol Neurobiol 36:167-179.

Hock C, Villringer K, Müller-Spahn F, Wenzel R, Heekeren H, Schuh-Hofer S, Hofmann M, Minoshima S, Schwaiger M, Dirnagl U, Villringer A (1997) Decrease in parietal cerebral hemoglobin oxygenation during performance of a verbal fluency task in patients with Alzheimer's disease monitored by means of near-infrared spectroscopy (NIRS)-correlation with simultaneous rCBF-PET measurements. Brain Res 755:293-303.

Hsia AY, Masliah E, McConlogue L, Yu GQ, Tatsuno G, Hu K, Kholodenko D, Malenka RC, Nicoll RA, Mucke L (1999) Plaque-independent disruption of neural circuits in Alzheimer's disease mouse models. Proc Natl Acad Sci U S A 96:3228-3233.

Iadecola C (2013) The pathobiology of vascular dementia. Neuron 80:844866.

Iadecola C, Zhang F, Xu X (1993) Role of nitric oxide synthase-containing vascular nerves in cerebrovasodilation elicited from cerebellum. Am J Physiol 264:R738-746.

Iadecola C, Zhang F, Xu X (1995) Inhibition of inducible nitric oxide synthase ameliorates cerebral ischemic damage. Am J Physiol 268:R286R292.

Iturria-Medina Y, Sotero RC, Toussaint PJ, Mateos-Pérez JM, Evans AC (2016) Early role of vascular dysregulation on late-onset Alzheimer's disease based on multifactorial data-driven analysis. Nat Commun 7:11934.

Jahrling JB, Lin AL, DeRosa N, Hussong SA, Van Skike CE, Girotti M, Javors M, Zhao Q, Maslin LA, Asmis R, Galvan V (2018) mTOR drives cerebral blood flow and memory deficits in LDLR(-/-) mice modeling atherosclerosis and vascular cognitive impairment. J Cereb Blood Flow Metab 38:58-74.

Joo IL, Lai AY, Bazzigaluppi P, Koletar MM, Dorr A, Brown ME, Thomason LA, Sled JG, McLaurin J, Stefanovic B (2017) Early neurovascular dysfunction in a transgenic rat model of Alzheimer's disease. Sci Rep 7:46427.

Kato S, Kawahara R, Yasuda M, Amagase K, Takeuchi K (2009) Aggravation of cold-restraint stress-induced gastric lesions in adjuvant arthritic rats: pathogenic role of inducible and endothelial nitric oxide. J Pharmacol Sci 111:244-252.

Kisler K, Nelson AR, Montagne A, Zlokovic BV (2017) Cerebral blood flow regulation and neurovascular dysfunction in Alzheimer disease. Nat Rev Neurosci 18:419-434.

Kitaura H, Uozumi N, Tohmi M, Yamazaki M, Sakimura K, Kudoh M, Shimizu T, Shibuki K (2007) Roles of nitric oxide as a vasodilator in neurovascular coupling of mouse somatosensory cortex. Neurosci Res 59:160-171.

Klakotskaia D, Agca C, Richardson RA, Stopa EG, Schachtman TR, Agca Y (2018) Memory deficiency, cerebral amyloid angiopathy, and amyloid- $\beta$ plaques in APP + PS1 double transgenic rat model of Alzheimer's disease. PloS one 13:e195469.

Kocharyan A, Fernandes P, Tong XK, Vaucher E, Hamel E (2008) Specific subtypes of cortical GABA interneurons contribute to the neurovascular coupling response to basal forebrain stimulation. J Cereb Blood Flow Metab 28:221-231.

Lecrux C, Hamel E (2011) The neurovascular unit in brain function and disease. Acta Physiol (Oxf) 203:47-59.

Leithner C, Royl G, Offenhauser N, Füchtemeier M, Kohl-Bareis M, Villringer A, Dirnagl U, Lindauer U (2010) Pharmacological uncoupling of activation induced increases in CBF and CMRO2. J Cereb Blood Flow Metab 30:311-322.

Lin A-L, Zheng W, Halloran JJ, Burbank RR, Hussong SA, Hart MJ, Javors M, Shih Y-YI, Muir E, Solano Fonseca R, Strong R, Richardson AG, Lechleiter JD, Fox PT, Galvan V (2013) Chronic rapamycin restores brain vascular integrity and function through NO synthase activation and improves memory in symptomatic mice modeling Alzheimer's disease. J Cereb Blood Flow Metab 33:1412-1421.

Lin AL, Jahrling JB, Zhang W, DeRosa N, Bakshi V, Romero P, Galvan V, Richardson A (2017) Rapamycin rescues vascular, metabolic and learning deficits in apolipoprotein E4 transgenic mice with pre-symptomatic Alzheimer's disease. J Cereb Blood Flow Metab 37:217-226.

Lindauer U, Megow D, Matsuda H, Dirnagl U (1999) Nitric oxide: a modulator, but not a mediator, of neurovascular coupling in rat somatosensory cortex. Am J Physiol 277:H799-811.

Lourenço CF, Ledo A, Barbosa RM, Laranjinha J (2017) Neurovascular uncoupling in the triple transgenic model of Alzheimer's disease: impaired cerebral blood flow response to neuronal-derived nitric oxide signaling. Exp Neurol 291:36-43.

Lubomirov LT, Papadopoulos S, Pütz S, Welter J, Klöckener T, Weckmüller K, Ardestani MA, Filipova D, Metzler D, Metzner H, Staszewski J, Zittrich S, Gagov H, Schroeter MM, Pfitzer G (2017) Aging-related alterations in eNOS and nNOS responsiveness and smooth muscle reactivity of murine basilar arteries are modulated by apocynin and phosphorylation of myosin phosphatase targeting subunit-1. J Cereb Blood Flow Metab 37:1014-1029. 
MacVicar BA, Newman EA (2015) Astrocyte regulation of blood flow in the brain. Cold Spring Harb Perspect Biol 7:a020388.

Majumder S, Richardson A, Strong R, Oddo S (2011) Inducing autophagy by rapamycin before, but not after, the formation of plaques and tangles ameliorates cognitive deficits. PLoS One 6:e25416.

Merlini M, Meyer EP, Ulmann-Schuler A, Nitsch RM (2011) Vascular $\beta$-amyloid and early astrocyte alterations impair cerebrovascular function and cerebral metabolism in transgenic $\operatorname{arcA} \beta$ mice. Acta Neuropathol 122:293-311.

Mishra A, Reynolds JP, Chen Y, Gourine AV, Rusakov DA, Attwell D (2016) Astrocytes mediate neurovascular signaling to capillary pericytes but not to arterioles. Nat Neurosci 19:1619-1627.

Mucke L, Masliah E, Yu GQ, Mallory M, Rockenstein EM, Tatsuno G, Hu K, Kholodenko D, Johnson-Wood K, McConlogue L (2000) High-level neuronal expression of a $\beta_{1-42}$ in wild-type human amyloid protein precursor transgenic mice: synaptotoxicity without plaque formation. J Neurosci 20:4050-4058.

Muñoz MF, Puebla M, Figueroa XF (2015) Control of the neurovascular coupling by nitric oxide-dependent regulation of astrocytic $\mathrm{Ca} 2+$ signaling. Front Cell Neurosci 9:59.

Nathan C, Calingasan N, Nezezon J, Ding A, Lucia MS, La Perle K, Fuortes M, Lin M, Ehrt S, Kwon NS, Chen J, Vodovotz Y, Kipiani K, Beal MF (2005) Protection from Alzheimer's-like disease in the mouse by genetic ablation of inducible nitric oxide synthase. J Exp Med 202:1163-1169.

Nicolakakis N, Aboulkassim T, Ongali B, Lecrux C, Fernandes P, Rosa-Neto P, Tong XK, Hamel E (2008) Complete rescue of cerebrovascular function in aged Alzheimer's disease transgenic mice by antioxidants and pioglitazone, a peroxisome proliferator-activated receptor gamma agonist. J Neurosci 28:9287-9296.

Ongali B, Nicolakakis N, Tong XK, Aboulkassim T, Papadopoulos P, RosaNeto P, Lecrux C, Imboden H, Hamel E (2014) Angiotensin II type 1 receptor blocker losartan prevents and rescues cerebrovascular, neuropathological and cognitive deficits in an Alzheimer's disease model. Neurobiol Dis 68:126-136.

Overend J, Martin W (2007) Differential effects of nitric oxide synthase inhibitors on endothelium-dependent and nitrergic nerve-mediated vasodilatation in the bovine ciliary artery. Br J Pharmacol 150:488-493.

Ozcelik S, Fraser G, Castets P, Schaeffer V, Skachokova Z, Breu K, Clavaguera F, Sinnreich M, Kappos L, Goedert M, Tolnay M, Winkler DT (2013) Rapamycin attenuates the progression of tau pathology in P301S tau transgenic mice. PLoS One 8:e62459.

Park L, Koizumi K, El Jamal S, Zhou P, Previti ML, Van Nostrand WE, Carlson G, Iadecola C (2014) Age-dependent neurovascular dysfunction and damage in a mouse model of cerebral amyloid angiopathy. Stroke 45:1815-1821.

Parodi-Rullán R, Sone JY, Fossati S (2019) Endothelial mitochondrial dysfunction in cerebral amyloid angiopathy and Alzheimer's disease. J Alzheimers Dis 72:1019-1039.

Pierce A, Podlutskaya N, Halloran JJ, Hussong SA, Lin PY, Burbank R, Hart MJ, Galvan V (2013) Over-expression of heat shock factor 1 phenocopies the effect of chronic inhibition of TOR by rapamycin and is sufficient to ameliorate Alzheimer's-like deficits in mice modeling the disease. J Neurochem 124:880-893.

Pigott B, Bartus K, Garthwaite J (2013) On the selectivity of neuronal NOS inhibitors. Br J Pharmacol 168:1255-1265.

Pritchard KA Jr, Ackerman AW, Gross ER, Stepp DW, Shi Y, Fontana JT, Baker JE, Sessa WC (2001) Heat shock protein 90 mediates the balance of nitric oxide and superoxide anion from endothelial nitric-oxide synthase. J Biol Chem 276:17621-17624.

Rancillac A, Geoffroy H, Rossier J (2012) Impaired neurovascular coupling in the APPxPS1 mouse model of Alzheimer's disease. Curr Alzheimer Res 9:1221-1230.

Rombouts SA, Barkhof F, Veltman DJ, Machielsen WC, Witter MP, Bierlaagh MA, Lazeron RH, Valk J, Scheltens P (2000) Functional MR imaging in Alzheimer's disease during memory encoding. AJNR Am J Neuroradiol 21:1869-1875.

Rombouts SARB, Goekoop R, Stam CJ, Barkhof F, Scheltens P (2005) Delayed rather than decreased BOLD response as a marker for early Alzheimer's disease. Neuroimage 26:1078-1085.

Rosenblum WI (1986) Endothelial dependent relaxation demonstrated in vivo in cerebral arterioles. Stroke 17:494-497.
Royea J, Zhang L, Tong XK, Hamel E (2017) Angiotensin IV receptors mediate the cognitive and cerebrovascular benefits of losartan in a mouse model of Alzheimer's disease. J Neurosci 37:5562-5573.

Royea J, Martinot P, Hamel E (2020) Memory and cerebrovascular deficits recovered following angiotensin IV intervention in a mouse model of Alzheimer's disease. Neurobiol Dis 134:104644.

Saganich MJ, Schroeder BE, Galvan V, Bredesen DE, Koo EH, Heinemann SF (2006) Deficits in synaptic transmission and learning in amyloid precursor protein (APP) transgenic mice require C-terminal cleavage of APP. J Neurosci 26:13428-13436.

Schindelin J, Arganda-Carreras I, Frise E, Kaynig V, Longair M, Pietzsch T, Preibisch S, Rueden C, Saalfeld S, Schmid B, Tinevez JY, White DJ, Hartenstein V, Eliceiri K, Tomancak P, Cardona A (2012) Fiji: an opensource platform for biological-image analysis. Nat Methods 9:676-682.

Shin HK, Jones PB, Garcia-Alloza M, Borrelli L, Greenberg SM, Bacskai BJ, Frosch MP, Hyman BT, Moskowitz MA, Ayata C (2007) Age-dependent cerebrovascular dysfunction in a transgenic mouse model of cerebral amyloid angiopathy. Brain 130:2310-2319.

Siman R, Cocca R, Dong Y (2015) The mTOR inhibitor rapamycin mitigates perforant pathway neurodegeneration and synapse loss in a mouse model of early-stage Alzheimer-type tauopathy. PLoS One 10:e0142340.

Song Y, Cardounel AJ, Zweier JL, Xia Y (2002) Inhibition of superoxide generation from neuronal nitric oxide synthase by heat shock protein 90: implications in NOS regulation. Biochemistry 41:10616-10622.

Sorond FA, Hurwitz S, Salat DH, Greve DN, Fisher ND (2013) Neurovascular coupling, cerebral white matter integrity, and response to cocoa in older people. Neurology 81:904-909.

Sousa JB, Fresco P, Diniz C (2015) Endothelial dysfunction impairs vascular neurotransmission in tail arteries. Neurochem Int 80:7-13.

Spilman P, Podlutskaya N, Hart MJ, Debnath J, Gorostiza O, Bredesen D, Richardson A, Strong R, Galvan V (2010) Inhibition of mTOR by rapamycin abolishes cognitive deficits and reduces amyloid-beta levels in a mouse model of Alzheimer's disease. PLoS One 5:e9979.

Stefanovic B, Schwindt W, Hoehn M, Silva AC (2007) Functional uncoupling of hemodynamic from neuronal response by inhibition of neuronal nitric oxide synthase. J Cereb Blood Flow Metab 27:741-754.

Stuehr DJ (1999) Mammalian nitric oxide synthases. Biochim Biophys Acta 1411:217-230.

Sun YX, Ji X, Mao X, Xie L, Jia J, Galvan V, Greenberg DA, Jin K (2014) Differential activation of mTOR complex 1 signaling in human brain with mild to severe Alzheimer's disease. J Alzheimers Dis 38:437-444.

Sweeney MD, Kisler K, Montagne A, Toga AW, Zlokovic BV (2018) The role of brain vasculature in neurodegenerative disorders. Nat Neurosci 21:1318-1331.

Tarantini S, Hertelendy P, Tucsek Z, Valcarcel-Ares MN, Smith N, Menyhart A, Farkas E, Hodges EL, Towner R, Deak F, Sonntag WE, Csiszar A, Ungvari Z, Toth P (2015) Pharmacologically-induced neurovascular uncoupling is associated with cognitive impairment in mice. J Cereb Blood Flow Metab 35:1871-1881.

Tarantini S, Tran CHT, Gordon GR, Ungvari Z, Csiszar A (2017a) Impaired neurovascular coupling in aging and Alzheimer's disease: contribution of astrocyte dysfunction and endothelial impairment to cognitive decline. Exp Gerontol 94:52-58.

Tarantini S, Fulop GA, Kiss T, Farkas E, Zölei-Szénási D, Galvan V, Toth P, Csiszar A, Ungvari Z, Yabluchanskiy A (2017b) Demonstration of impaired neurovascular coupling responses in TG2576 mouse model of Alzheimer's disease using functional laser speckle contrast imaging. GeroScience 39:465-473.

Thorns V, Hansen L, Masliah E (1998) nNOS expressing neurons in the entorhinal cortex and hippocampus are affected in patients with Alzheimer's disease. Exp Neurol 150:14-20.

Tong X-K, Nicolakakis N, Fernandes P, Ongali B, Brouillette J, Quirion R, Hamel E (2009) Simvastatin improves cerebrovascular function and counters soluble amyloid-beta, inflammation and oxidative stress in aged APP mice. Neurobiol Dis 35:406-414.

Tong XK, Lecrux C, Rosa-Neto P, Hamel E (2012) Age-dependent rescue by simvastatin of Alzheimer's disease cerebrovascular and memory deficits. J Neurosci 32:4705-4715.

Toth P, Tarantini S, Davila A, Valcarcel-Ares MN, Tucsek Z, Varamini B, Ballabh P, Sonntag WE, Baur JA, Csiszar A, Ungvari Z (2015) Purinergic glio-endothelial coupling during neuronal activity: role of $\mathrm{P} 2 \mathrm{Y} 1$ receptors 
and eNOS in functional hyperemia in the mouse somatosensory cortex. Am J Physiol Heart Circ Physiol 309:H1837-H1845.

Tramutola A, Triplett JC, Di Domenico F, Niedowicz DM, Murphy MP, Coccia R, Perluigi M, Butterfield DA (2015) Alteration of mTOR signaling occurs early in the progression of Alzheimer disease (AD): analysis of brain from subjects with pre-clinical $\mathrm{AD}$, amnestic mild cognitive impairment and late-stage AD. J Neurochem 133:739-749.

Van Skike CE, Galvan V (2018) A perfect sTORm: the role of the mammalian target of rapamycin (mTOR) in cerebrovascular dysfunction of Alzheimer's disease: a mini-review. Gerontology 64:205-211.

Van Skike CE, Jahrling JB, Olson AB, Sayre NL, Hussong SA, Ungvari Z, Lechleiter JD, Galvan V (2018) Inhibition of mTOR protects the bloodbrain barrier in models of Alzheimer's disease and vascular cognitive impairment. Am J Physiol Heart Circ Physiol 314:H693-H703.

Van Skike CE, Lin AL, Roberts Burbank R, Halloran JJ, Hernandez SF, Cuvillier J, Soto VY, Hussong SA, Jahrling JB, Javors MA, Hart MJ, Fischer KE, Austad SN, Galvan V (2020) mTOR drives cerebrovascular, synaptic, and cognitive dysfunction in normative aging. Aging Cell 19: e13057.

Vodovotz Y, Lucia MS, Flanders KC, Chesler L, Xie QW, Smith TW, Weidner J, Mumford R, Webber R, Nathan C, Roberts AB, Lippa CF, Sporn MB (1996) Inducible nitric oxide synthase in tangle-bearing neurons of patients with Alzheimer's disease. J Exp Med 184:1425-1433.

Wallace MN, Geddes JG, Farquhar DA, Masson MR (1997) Nitric oxide synthase in reactive astrocytes adjacent to beta-amyloid plaques. Exp Neurol 144:266-272.

Wilkinson JE, Burmeister L, Brooks SV, Chan CC, Friedline S, Harrison DE, Hejtmancik JF, Nadon N, Strong R, Wood LK, Woodward MA, Miller RA (2012) Rapamycin slows aging in mice. Aging Cell 11:675-682.
Winkler EA, Nishida Y, Sagare AP, Rege SV, Bell RD, Perlmutter D, Sengillo JD, Hillman S, Kong P, Nelson AR, Sullivan JS, Zhao Z, Meiselman HJ, Wendy RB, Soto J, Abel ED, Makshanoff J, Zuniga E, De Vivo DC, Zlokovic BV (2015) GLUT1 reductions exacerbate Alzheimer's disease vasculo-neuronal dysfunction and degeneration. Nat Neurosci 18:521530.

Wright AL, Zinn R, Hohensinn B, Konen LM, Beynon SB, Tan RP, Clark IA, Abdipranoto A, Vissel B (2013) Neuroinflammation and neuronal loss precede $\mathrm{A} \beta$ plaque deposition in the hAPP-J20 mouse model of Alzheimer's disease. PLoS One 8:e59586.

Wu Z, Hofman FM, Zlokovic BV (2003) A simple method for isolation and characterization of mouse brain microvascular endothelial cells. J Neurosci Methods 130:53-63.

Yang G, Chen G, Ebner TJ, Iadecola C (1999) Nitric oxide is the predominant mediator of cerebellar hyperemia during somatosensory activation in rats. Am J Physiol 277:R1760-R1770.

Zhang F, Xu S, Iadecola C (1995) Role of nitric oxide and acetylcholine in neocortical hyperemia elicited by basal forebrain stimulation: evidence for an involvement of endothelial nitric oxide. Neuroscience 69:11951204.

Zhang HQ, Fast W, Marletta MA, Martasek P, Silverman RB (1997) Potent and selective inhibition of neuronal nitric oxide synthase by $\mathrm{N}$ omegapropyl-L-arginine. J Med Chem 40:3869-3870.

Zhang Y, Bokov A, Gelfond J, Soto V, Ikeno Y, Hubbard G, Diaz V, Sloane L, Maslin K, Treaster S, Réndon S, van Remmen H, Ward W, Javors M, Richardson A, Austad SN, Fischer K (2014) Rapamycin extends life and health in C57BL/6 mice. J Gerontol A Biol Sci Med Sci 69:119-130.

Zlokovic BV (2011) Neurovascular pathways to neurodegeneration in Alzheimer's disease and other disorders. Nat Rev Neurosci 12:723-738. 